\title{
Detection and identification of explosives by surface enhanced Raman scattering
}

Félix Zapata $^{\text {a,b }}$, María López-López ${ }^{\text {a,b }}$, Carmen García-Ruiz ${ }^{\text {a,b, * }}$

${ }^{a}$ Department of Analytical Chemistry, Physical Chemistry and Chemical Engineering, University of Alcalá, Alcalá de Henares (Madrid), Spain.

${ }^{\mathrm{b}}$ University Institute of Research in Police Sciences (IUICP), University of Alcalá, Alcalá de Henares (Madrid), Spain.

E-mail: carmen.gruiz@uah.es; felix.zapata@uah.es

Cite: F. Zapata, M. López-López, C. García-Ruiz, Detection and identification of explosives by surface enhanced Raman scattering, Appl. Spectrosc. Reviews. 51:3 (2016) 207-242. DOI: $10.1080 / 05704928.2015 .1118637$ 


\begin{abstract}
Surface Enhanced Raman Scattering (SERS) has undergone an important development over the last few years, particularly in the detection and identification of extremely low traces of explosives. The large number of studies and results generated by this increasing research makes a comprehensive overview necessary. This work reviews in detail that research focused on the identification of explosives by SERS, including TNT, DNT, RDX, PETN, TATP, HMTD, perchlorate, etc. either in bulk state, in solution or in vapour phase. In brief, TNT and DNT have been widely studied by SERS due to its aromatic structure and LODs down to $5-10 \mathrm{zg}$ and $10^{-17}-10^{-13} \mathrm{M}$ have been achieved. The other explosives have been quite less researched; therefore, few results are available to be compared and a bit more modest LODs have been reached such as $10^{-13} \mathrm{M}$ for RDX, $10^{-4}$ $\mathrm{M}$ for TATP, $5 \mathrm{pg}$ for PETN, or $10^{-9} \mathrm{M}$ for perchlorate. In addition, the challenges of detecting both explosives vapours and perchlorate anion by SERS are thoroughly discussed.
\end{abstract}




\section{Introduction}

Explosives are increasingly giving cause for concern worldwide because of terrorism expansion as an alarming global threat [1]. In brief, explosives are chemical compounds which have a great destruction power even in small amounts due to their fast decomposition process (high velocity of detonation) producing large amounts of gases, heat and rapid expansion of matter [1, 2]. The detection and identification of explosives is highly required on different fields including homeland security, which takes care of preventing potential threats by detecting suspicious-looking explosive devices before their explosion, as well as the police investigations which deal with the crime scene investigation process when the explosion unluckily occurs $[1,3]$.

Mass spectrometry is a well-known technique used for this purpose due to its high selectivity, sensitivity and its unrivalled limits of detection (LODs) [1, 3]. However, some disadvantageous aspects including sample treatment and the highly controlled conditions needed to achieve accurate results make mass spectrometry difficult to be used in realtime and on field detection. These tasks, which require extremely fast detection procedures, seem to be suitable for spectroscopic techniques.

Spectroscopic techniques such as infrared (IR) and Raman spectroscopy are particularly fast (seconds) as well as they have great selectivity due to the specific spectral signature from each chemical compound known as IR or Raman fingerprint. Over the last years, the identification of explosives by IR and Raman spectroscopy [3-10] has been deeply investigated. In sum, these studies have proved the suitability of IR and Raman spectroscopy to identify explosive compounds, particularly when they are at high concentrations. This fact is explained by a lack of sensitivity, compared to other analytical techniques, which does not allow for the detection of explosives at trace level. Fortunately, Raman spectroscopy may have overcome that limitation through a form of Raman methodology called Surface Enhanced Raman Scattering (SERS), which improves LODs of Raman spectroscopy several orders of magnitude [11-14].

SERS has undergone an important development since it was discovered 40 years ago by Fleischmann et al. when they realized that Raman intensity was surprisingly enhanced when pyridine molecules were close to a metal surface (silver electrode) [15]. Nowadays SERS phenomenon is known to be caused by two factors: an electromagnetic effect due to surface plasmons (collective delocalized electron oscillations) which exist at rough 
metal surfaces, and an increased polarizability of adsorbed molecules on rough metal surfaces due to a charge transfer mechanism derived from that interaction [11-14]. The electromagnetic mechanism is responsible for the main enhancement (enhancement factor (EF) up to 108) whereas the enhancement due to the increase of polarizability is believed to be quite lower (EF up to $10^{2}$ ) [13]. Interestingly, experimental EFs are usually calculated by comparing SERS intensity with normal Raman intensity. However, these estimates suffer from the fact that we do not know the number of target molecules really involved in the SERS process which contribute to the Raman signal [13]. Therefore, EF estimates must not be considered as accurate values, but rough values which are useful to tentatively check the SERS enhancement of the target molecule. However, it seems that SERS technique does not really take off beyond academic field [16]. One main key challenge must be overcome first: the development of stable, selective, and reproducible SERS-active substrates that provide a large Raman intensity enhancement even for molecules whose signal seems not to show any SERS enhancement [13]. In fact, SERS seems to be suitable for only few molecules. Nevertheless, homeland security deals with a large variety of chemical compounds [16]. In addition, homeland security requires minimal error, extreme LODs, real-time, and on field detection. This article will assess if SERS fulfils all these requirements.

Particularly, this work reviews those studies focused on the identification of explosives by SERS, a Raman spectroscopy working mode which has been largely increased for the last twenty years. First, this article pursues to summarize those studies which investigate the identification of explosives either in bulk state or in solution; to show the potential of SERS for vapour detection of explosives through SERS sensors as chemical noses, and to review the existing problematic about the detection of the perchlorate anion in water, a hazardous chemical which usually comes from explosives and pyrotechnic devices.

\section{Identification of explosives by SERS}

A wide variety of explosive compounds have been investigated by SERS for the last two decades. Table 1 summarizes all this research through a comprehensive revision, which includes the chemical structure of each explosive, its characteristic normal Raman bands (obtained from the Raman spectra database generated by our laboratory, the experimental SERS bands and LODs achieved by using each SERS substrate in the collected 
references. Table 1 is discussed along this section, which has been structured according to the explosive studied. First, TNT (trinitrotoluene) and DNT (2,4-dinitrotoluene) are reviewed (which have been widely investigated) with some mentions toward other similar nitroaromatic compounds such as TNB (trinitrobenzene), DNB (dinitrobenzene), NT (nitrotoluene), and NB (nitrobenzene). Second, RDX (hexogen), HMX (octogen), PETN (penthrite), and other military and commercial explosives including NG (nitroglycerin), tetryl, EGDN (ethylene glycol dinitrate), potassium nitrate, DNAN (2,4- dinitroanisole), NTO (3-nitro-1,2,4-triazol-3-one), and HNIW (hexanitrohexaaza-isowurtzitane) are grouped, and finally, peroxide explosives including TATP (triacetone triperoxide) and HMTD (hexamethylene triperoxide diamine) are discussed. 
Table 1. Comprehensive summary review about explosives identification by SERS containing the chemical structure of each explosive, its characteristic normal Raman bands and its SERS bands and the LODs achieved by using each SERS substrate from the respective reference.

\begin{tabular}{|c|c|c|c|c|c|c|}
\hline Explosive & Chemical structure & $\begin{array}{c}\text { Characteristic } \\
\text { normal Raman } \\
\text { bands }\left(\mathrm{cm}^{-1}\right)\end{array}$ & SERS bands $\left(\mathrm{cm}^{-1}\right)$ & SERS substrate used & $\begin{array}{l}\text { LOD or minimum } \\
\text { amount analysed } \\
\text { in molar conc., } \\
\text { mass or both }\end{array}$ & Ref. \\
\hline \multirow{14}{*}{ TNT } & \multirow{14}{*}{$\mathrm{CH}_{3}$} & \multirow{14}{*}{$\begin{array}{c}1616,1533 \\
1357,1209 \\
1085,820,790 \\
324\end{array}$} & $1360,1270-1230,1000$ & AuNPs \& AgNPs & $10^{-7} \mathrm{M}(1 \mathrm{pg})$ & 17 \\
\hline & & & - & AuNPs, AgNPs \& Au foil & $4.4 \times 10^{-8} \mathrm{M}$ & 18 \\
\hline & & & $1600,1359,1275,1204,1000$ & AgNPs & $1 \mathrm{fg}$ & 19,20 \\
\hline & & & 1390, 1238, 1006 & AgNPs & $10^{-10} \mathrm{M}$ & 23 \\
\hline & & & $\begin{array}{l}1579,1370,1147 / \\
1525,1425,1375,1260\end{array}$ & AgNPs & $4 \times 10^{-10} \mathrm{M}$ & 24 \\
\hline & & & $1362,1534,1275,717$ & AuNPs on filter paper & 94 pg & 25 \\
\hline & & & $\begin{array}{l}1611,1535,1360,1210,821, \\
790\end{array}$ & Klarite & $4.4 \times 10^{-5} \mathrm{M}(16 \mathrm{pg})$ & $26-31$ \\
\hline & & & $1356,1200,828$ & APTES-MIP-Klarite & $3 \times 10^{-6} \mathrm{M}$ & 34,35 \\
\hline & & & $\begin{array}{l}1615,1534,1360,1210,1026, \\
940,909,790\end{array}$ & Cysteine-AuNPs & $2 \times 10^{-12} \mathrm{M}$ & 36 \\
\hline & & & $1590,1090,1000$ & Cysteamine-AgNPs & $10^{-4} \mathrm{M}(5 \mathrm{pg})$ & 37 \\
\hline & & & 1390 (PATP-TNT), 1369 & PATP-AgNPs & $1.5 \times 10^{-17} \mathrm{M}$ & 38 \\
\hline & & & $\begin{array}{l}\text { 1616, 1364, 1213, 1167, 914, } \\
794\end{array}$ & EHDAB-AuNPs & $10^{-9} \mathrm{M}$ & 39 \\
\hline & & & 1359 & $\mathrm{TiO}_{2}$ & 100 pg & $\begin{array}{c}43,44 \\
46\end{array}$ \\
\hline & & & $1370-1300,1006,850-820$ & $\mathrm{Au} / \mathrm{AgNPs}, \mathrm{TiO}_{2} / \mathrm{AgNPs}$ & $10^{-12} \mathrm{M}(0.1 \mathrm{fg})$ & 47,48 \\
\hline
\end{tabular}




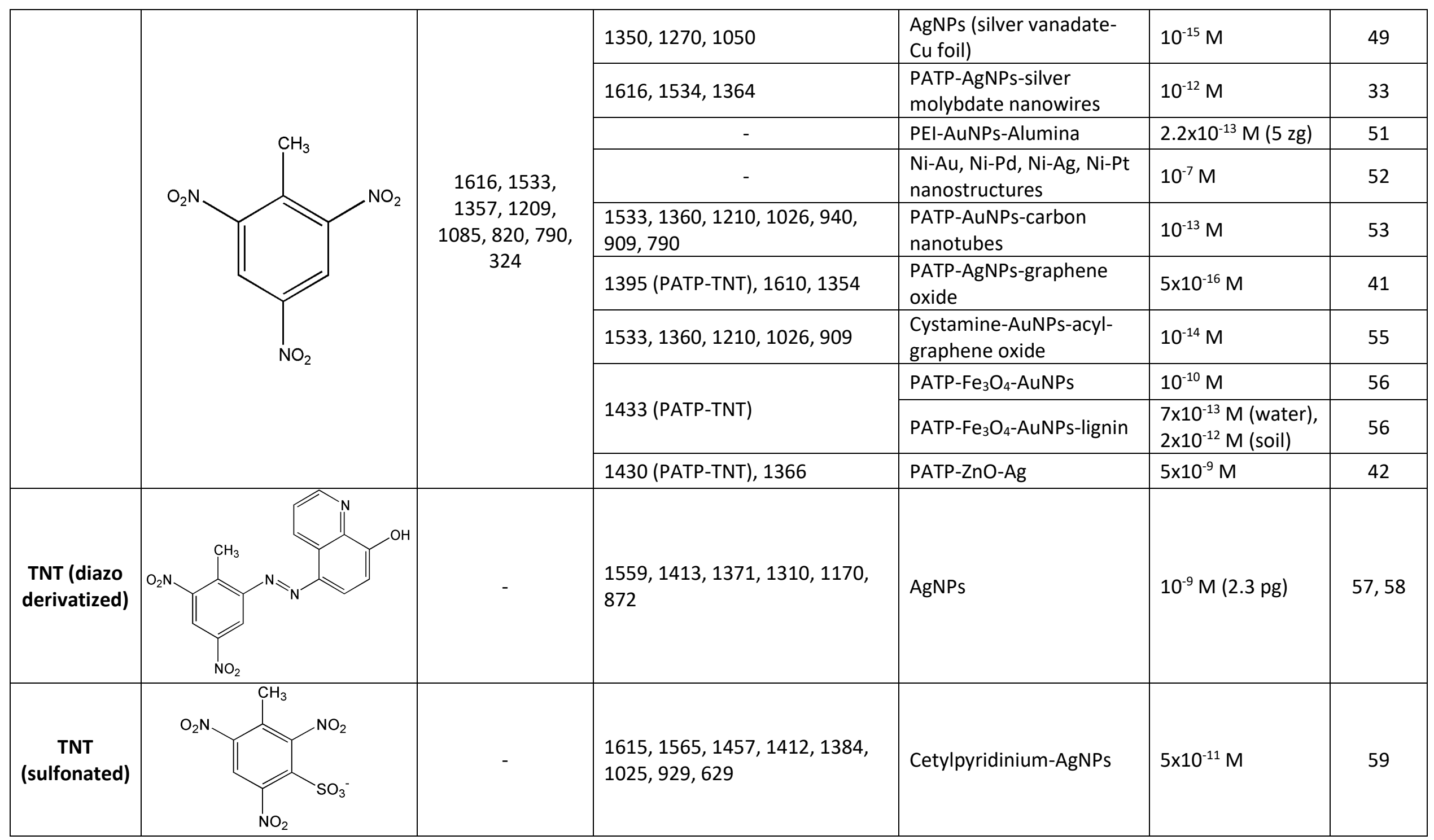




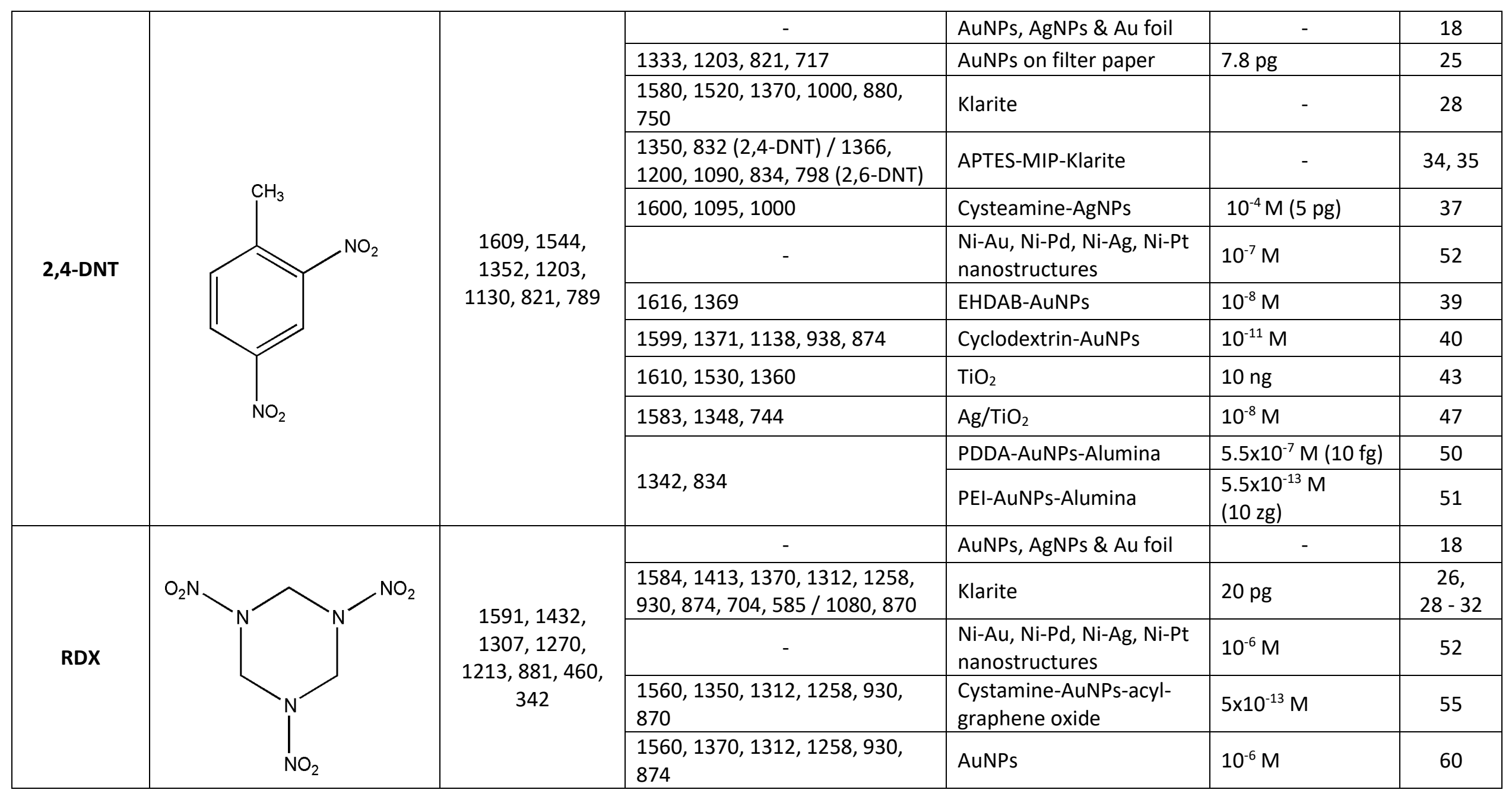




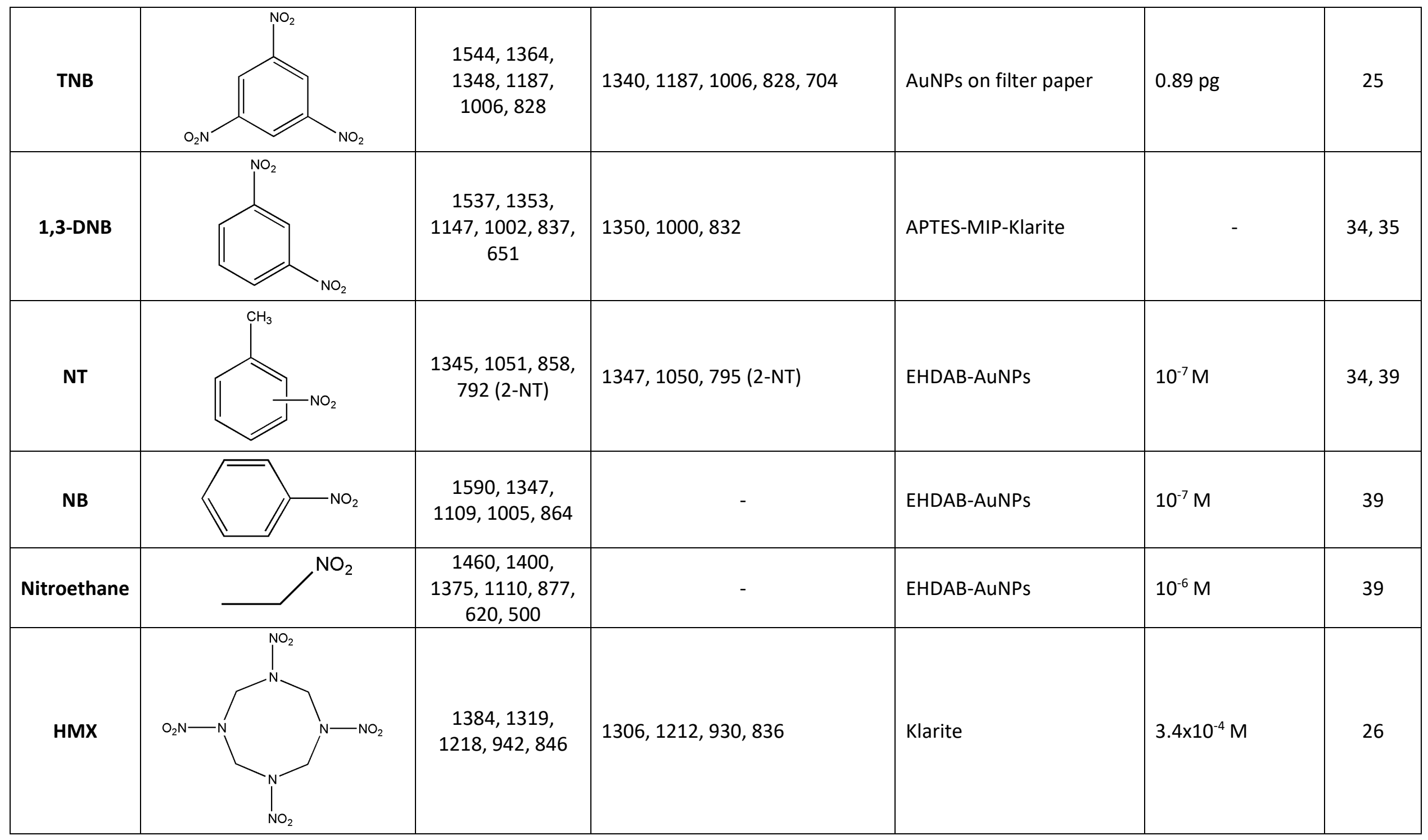




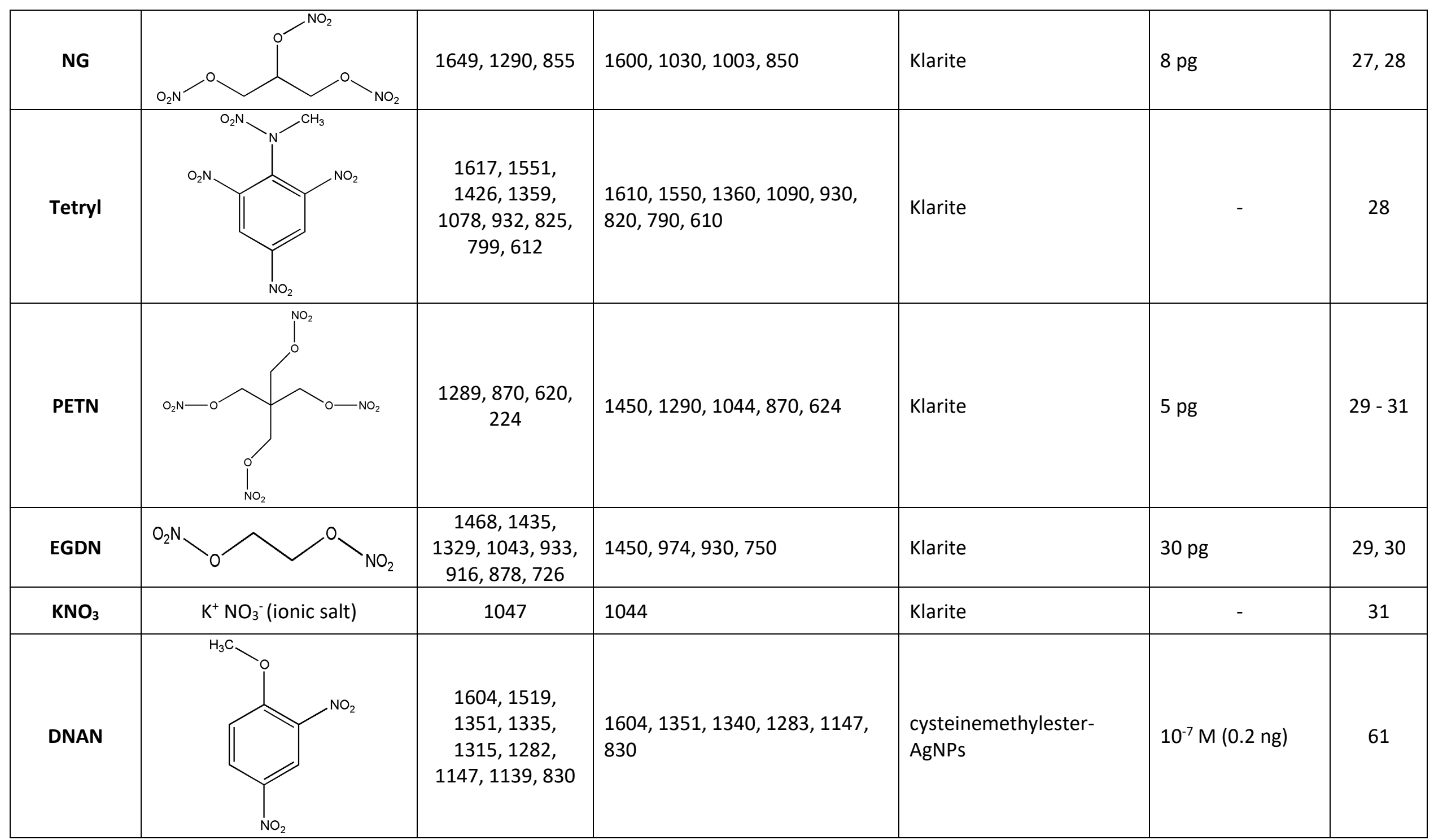




\begin{tabular}{|c|c|c|c|c|c|c|}
\hline NTO & $L^{\mathrm{N}}=\mathrm{N}$ & $\begin{array}{c}1593,1542 \\
1470,1356, \\
1327,1099 \\
1013,825,745 \\
723,580,467\end{array}$ & $\begin{array}{l}\text { 1532, 1479, 1387, 1309, 1099, } \\
1061,846\end{array}$ & $\begin{array}{l}\text { functionalized Ag } \\
\text { nanofilm }\end{array}$ & $\begin{array}{l}2.7 \times 10^{-7} \mathrm{M} \\
(0.35 \mathrm{ng})\end{array}$ & 62 \\
\hline HNIW & & $\begin{array}{c}1626,1329 \\
1297,1263,842 \\
795\end{array}$ & $\begin{array}{l}1633,1332,1299,1267,1094, \\
1002,935,838,810,799\end{array}$ & AgNPs & $4 \times 10^{-10} \mathrm{M}$ & 24 \\
\hline TATP & & $\begin{array}{c}1449,944,861 \\
551,398,297\end{array}$ & $1450,1020,1004,840$ & Klarite & $\begin{array}{l}4.5 \times 10^{-4} \mathrm{M} \\
(400 \mathrm{pg})\end{array}$ & 27,28 \\
\hline HMTD & & $\begin{array}{l}1396,946,770 \\
410,294\end{array}$ & 1266 & PEI-AuNPs-Alumina & $1 \mathrm{pg}$ & 51 \\
\hline
\end{tabular}

APTES: (3-Aminopropyl)triethoxysilane; DNAN: 2,4-Dinitroanisole; DNB: Dinitrobenzene; DNT: Dinitrotoluene; EGDN: Ethylene glycol dinitrate; EHDAB: Ethylhexadecyl-dimethyl-ammonium bromide; HMTD: Hexamethylene triperoxide diamine; HMX: Octogen; HNIW: Hexanitrohexaazaisowurtzitane; MIP: Molecularly imprinted polymer; NB: Nitrobenzene; NG: Nitroglycerin; NPs: Nanoparticles; NT: Nitrotoluene; NTO: 3-Nitro-1,2,4-triazol-3-one; PATP: p-Aminothiophenol; PDDA: Poly(diallyldimethylammonium chloride; PEI: Polyethylenimine; PETN: Penthrite (Pentaerythritol tetranitrate); RDX: Hexogen; TATP: Triacetone triperoxide; TNB: Trinitrobenzene; TNT: Trinitrotoluene. 


\section{TNT and DNT}

TNT, one of the military explosives most used worldwide, has been the explosive most studied over the years by SERS. In fact, the research about the detection and identification of explosives by SERS began trough the analysis of TNT in 1995 [17]. The main reason of its great use in SERS is due to the large enhancement factor result of the interaction between TNT molecules and Au/Ag nanoparticles (NPs). In that study, Kneipp et al. examined both gold and silver nanoparticles in order to determine the ideal ones for the detection of TNT. A laser of $830 \mathrm{~nm}$ wavelength at $120 \mathrm{~mW}$ power was used to obtain the spectra. First of all the Raman signature of TNT was established and its characteristic bands located at 1648, 1570, 1360, 1204, 837, and $752 \mathrm{~cm}^{-1}$ were identified. The band at $1360 \mathrm{~cm}^{-1}$ attributed to the $\mathrm{NO}_{2}$ stretching mode was the most intense. Then, TNT solutions at different concentrations from $0.01 \mathrm{M}$ to $7.5 \times 10^{-7} \mathrm{M}$ were analyzed in presence of colloidal AuNPs or AgNPs. Sodium chloride was also added to the solutions to increase SERS effect through the interaction of TNT molecules and colloidal NPs. The appearance of a new strong band at $800 \mathrm{~cm}^{-1}$ indicated a high aggregation of AgNPs which hindered the identification of TNT. Therefore, AuNPs were chosen to continue the study since their presence did not transform so drastically the characteristic Raman signature of TNT. TNT was detected down to $10^{-7} \mathrm{M}$ using AuNPs, which corresponded to $1 \mathrm{pg}$. An enhancement factor of 105 was assessed for AuNPs at that concentration [17].

A few years later, other different SERS substrates besides colloidal AuNPs such as Au or $\mathrm{Ag}$ foils and Au-coated microspheres were studied for TNT, DNT, and RDX detection [18]. A better reproducibility was obtained with the $\mathrm{Au}$ foil due to the ease of $\mathrm{Ag}$ roughening. Three different laser wavelengths were tested $(514,676$, and $785 \mathrm{~nm})$ in order to determine the optimum wavelength when using the Au foil. The $785 \mathrm{~nm}$ wavelength was selected due to both great sample signal and low fluorescence background [18]. Colloidal AuNPs with different sizes (diameters of 5, 10, 15, and 20 $\mathrm{nm}$ ) were also studied for TNT detection. According to authors, the bigger they were, the larger EF they provided; at least within that sizes range. TNT was detected down to 10 ppb by using the biggest colloidal AuNPs (20 nm). Interestingly, Au-coated microspheres supplied the worst results. No SERS signal was produced when coating layers were thicker than $50 \mathrm{~nm}$ or thinner than $10 \mathrm{~nm}$. In addition, a $25 \mathrm{~nm}$ coating, which gave quite reproducible results, provided a SERS intensity at least a factor of two lower than it was for Au foil [18]. 
These studies demonstrated by the first time the small amounts of explosive compounds which can be detected by SERS technique and it marked the beginning of a research line whose main objective is the improvement of LODs of explosives by using different SERS substrates. Thus, that research gathers a large number of studies where small quantities of TNT and usually DNT were detected by SERS supported by SERS substrates either based on $\mathrm{Au} / \mathrm{Ag}$ or other novel compounds such as $\mathrm{Cu}$, $\mathrm{Ti}$, or graphene. The main improvements achieved up to now are reviewed below.

Regarding the use of colloidal AgNPs for TNT detection by SERS, Jerez Rozo et al. stated some interesting observations $[19,20]$. First, the addition of $\mathrm{NaCl}$ to the mixture of TNT and colloidal AgNPs solutions, as Kneipp et al. had previously reported [17], was proven to be essential to promote SERS effect. According to them, after Ag colloid preparation, colloidal AgNPs are negatively charged so an electrostatic repulsion between particles exists which prevents agglomeration. However, an increase in the ionic strength by the addition of a salt shortens the range of repulsion and facilitates the agglomeration, which is a desirable fact when TNT solution is added in order to promote the interaction between TNT molecules and AgNPs. That is why no noticeable SERS effect was observed in the absence of $\mathrm{NaCl}[19,20]$. They also optimized other relevant factors including size of AgNPs and $\mathrm{pH}$. The best results for TNT detection were obtained with AgNPs of 60-80 $\mathrm{nm}$ diameter at $\mathrm{pH}$ of 13.5. As they showed, the value of $\mathrm{pH}$ seems to be quite crucial for TNT trace detection since TNT signals almost disappeared at pH below 12 [19]. In fact, they realized that the colour of solution changed at $\mathrm{pH} 12$. This change was likely due to a chemical transformation of TNT, its alkaline hydrolysis at basic media, which was confirmed by high-performance liquid chromatography with UV/Vis detection (HPLCUV/Vis) [20]. Since these new products at $\mathrm{pH}$ over 12 were not chemically similar to TNT, Jerez-Rozo et al. concluded that the detection of TNT was achieved via an indirect method that involved the identification of TNT from its alkaline hydrolysis products [20]. Nevertheless, one might think that there are probably other molecules which also produce the same hydrolysis products do not allowing the unequivocal detection of TNT.

Jerez-Rozo et al. also demonstrated that the enhancement factor due to SERS effect is affected by the method used for Ag colloid preparation [19, 20]. In their study AgNPs were synthesized through two different chemical reduction methods, concretely the Lee and Meisel method based on citrate [21] and the Leopold and Lendl method based on hydroxylamine [22]. In accordance with their results, a larger enhancement of the TNT 
signal in the AgNPs reduced with citrate was observed. The fact that citrate is a stronger reducing agent than hydroxylamine and therefore there is a tighter control in the size of the NPs may explain it [19]. Jerez-Rozo et al. examined, as did Kneipp et al., the SERS effect due to both AuNPs and AgNPs [20]. According to their observations, AgNPs provided greater EFs than AuNPs, whereas AuNPs provided higher reproducibility. Therefore, a combination of AgNPs and AuNPs in the same substrate was used in order to exploit the advantages of both [20]. Thereby, the greatest LOD obtained for TNT by using the optimum conditions was $10 \mathrm{fg}[19,20]$. As the authors stated, the fact that SERS spectra of TNT did not differ much from the one taken in bulk meant that the enhanced signal was due to the electromagnetic effects and not because of chemical effects [19]. An improved method for Ag colloid preparation based on reduction with citrate was accomplished by Zhang et al. [23] by means of microwave heating during reduction. This procedure made the AgNPs preparation faster and removed stirring from the process. As had been previously reported, the addition of $\mathrm{NaCl}$ to AgNPs was essential to detect TNT. Concretely, the optimum concentration of $\mathrm{NaCl}$ to promote TNT SERS effect was found to be $0.9 \mathrm{M}$ [23]. In that study, $\mathrm{pH}$ was also studied and the better results for TNT detection were achieved by using pH 13 as Jerez-Rozo et al. had previously observed. According to authors, TNT undergoes an alkaline hydrolysis at that $\mathrm{pH}$, but its nitroaromatic structure is still retained, deduced from the characteristic Raman bands of nitro group and aromatic ring. Thereby, an LOD of $10^{-10} \mathrm{M}$ was accomplished for TNT [23]. A more innovative and ecological method for AgNPs preparation was developed by Sil et al. by using clove and pepper extracts as reducing agents instead of citrate [24]. In addition, $\mathrm{HCl}$ was added instead of $\mathrm{NaCl}$ to promote AgNPs aggregation. By using these bio-AgNPs, TNT and HNIW explosives were detected down to $4 \times 10^{-10} \mathrm{M}$. TNT showed an EF of $10^{9}$ for both clove- and pepper-reduced AgNPs whereas HNIW displayed an EF of $10^{8}$ for clove-reduced AgNPs and $10^{6}$ for pepper-reduced AgNPs [24].

These studies accomplished the SERS detection of TNT by mixing the TNT and NPs solutions and then placing a drop of the mixture onto a slide. However, in some studies the usual glass slides have been substituted for other materials in order to improve SERS effect such as lab filter paper [25]. In that study, AuNPs were deposited by using thermal inkjet technology onto the filter paper. This homemade SERS active substrate was tested for TNT, DNT, and TNB detection arising the LOD estimated values of $94 \mathrm{pg}$ for TNT, $7.8 \mathrm{pg}$ for DNT, and $0.89 \mathrm{pg}$ for TNB in the laser spot. The accuracy of these estimates 
are discussed below. In addition, a nonlinear direct correlation was found between intensity of the nitro Raman band and the analyte concentration, but it became linear through the plot $1 / \mathrm{I} v s 1 /$ (conc) [25].

Other substrates quite researched for the analysis of explosives by SERS include commercial SERS-active substrates such as Klarite (Klarite ${ }^{\mathrm{TM}}$, Renishaw), a silicon goldcoated chip. Calzzani et al. studied two different homemade gold-coated substrates in comparison with commercial Klarite for the detection of TNT, RDX, and HMX [26]. Those homemade substrates were an Au film and a gold-coated polystyrene nanospheres film consisting of AuNPs and gold-coated polystyrene nanospheres, respectively, covering a glass slide. TNT was the molecule used to evaluate the three substrates. In terms of EF, a value of $10^{4}$ and $10^{6}$ was achieved for $\mathrm{Au}$ and Au-polystyrene films respectively, whereas commercial Klarite reached $10^{8}$. The acetonitrile solvent from explosive solutions was observed to attack the polystyrene film. This fact most likely made EF values worse. By using Klarite, the LOD of TNT was found at $10 \mathrm{ppm}$ [26]. Botti et al. repeatedly used Klarite for the detection of a large variety of explosives by SERS including TNT [27-31], DNT [28], NG [27, 28], TATP [27, 28], RDX [28-31], Tetryl [28], PETN [29-31], EGDN [29, 30], and $\mathrm{KNO}_{3}$ [31]. The LOD achieved for TNT was calculated to be $200 \mathrm{pg}$ within the laser spot which came from $0.1 \mathrm{~mL}$ of $1 \mathrm{mg} / \mathrm{mL}$ TNT solution [27-29]. In subsequent studies, LOD for TNT was improved up to $20 \mathrm{pg}$ [30] and 16 pg [31]. Botti et al. also studied by SEM the TNT deposition among the surface of Klarite. Klarite surface consists of inverted pyramids array ordered nanostructures, as shown in Figure 1. In fact, Botti et al. found that inverted pyramids which contained the precipitate explosive where randomly distributed, as displayed in Figure 1 [29, 30, 32]. 


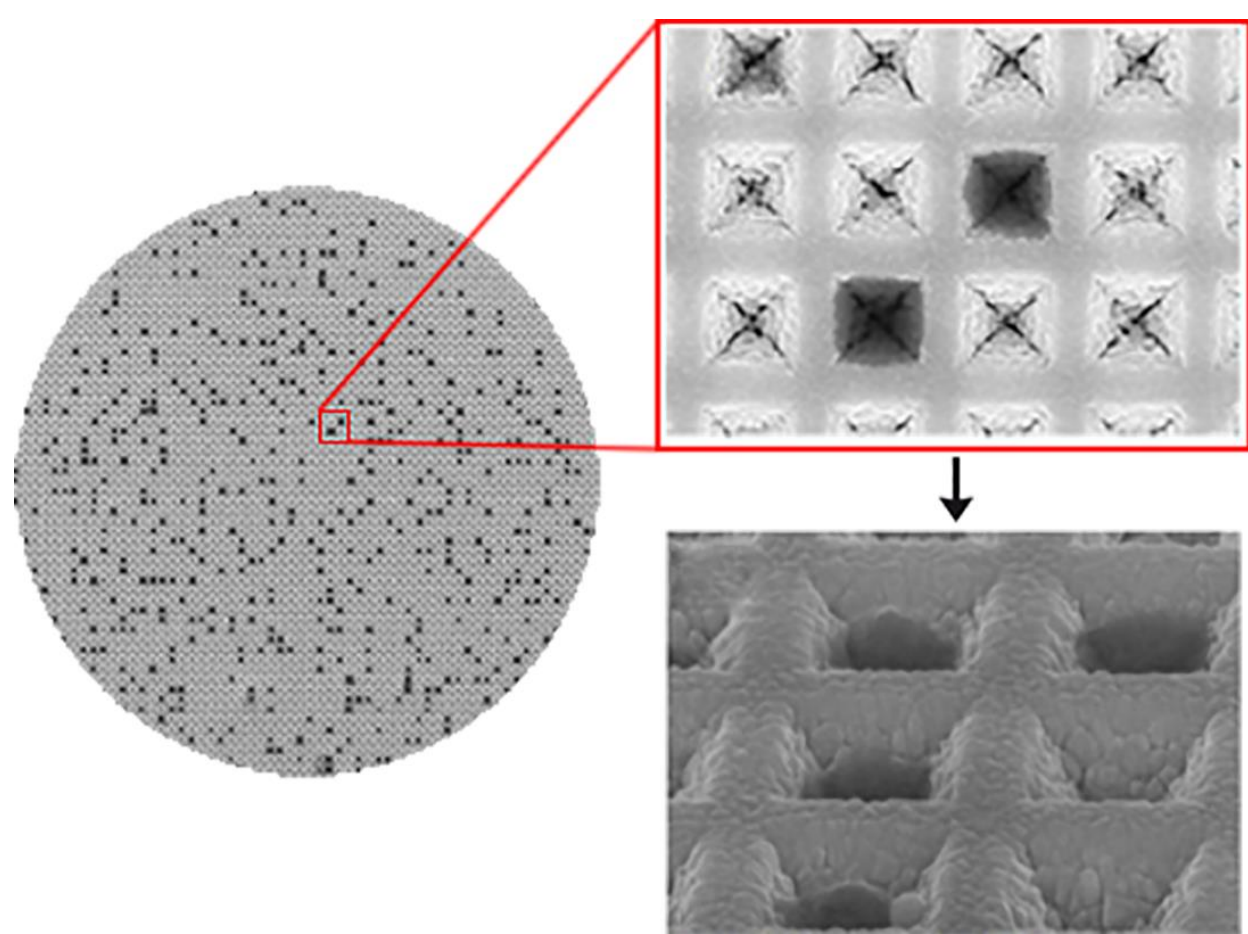

Figure 1. Scanning electron microscope image of Klarite substrate with TNT explosive residuals on the surface. Adapted with permission from Botti et al. (30) and Almaviva et al. (32).

This fact demonstrated that the precipitation of the explosive is not uniform. As consequence, we must realize that the estimated LOD, mathematically calculated from the total mass deposited along all the substrate area assuming a homogeneous distribution, may lead to inaccurate results. Therefore, these LOD estimations are noticeably overvalued because if there are empty areas, the spots that do contain the deposited analyte (the ones that produce SERS signal) have more mass than it was expected for a uniform distribution. However, all the studies reviewed in this work use this LOD estimation, probably because of the difficulty to know exactly the mass which is being analysed within the laser spot. Regarding the EF, Botti et al. pointed that EF for LOD cannot be correctly calculated from the intensity differences between using and without using SERS, because that small quantity of analyte is not detected without SERS [29]. However, it can be estimated through the following equation:

$$
E F=\frac{I_{S E R S} / N_{S E R S}}{I_{0} / N_{0}}
$$

where ISERS and $\mathrm{I}_{0}$ are the intensities of the same band for the SERS and Raman spectra, $\mathrm{N}_{0}$ is the number of molecules probed with the normal Raman scattering, and $\mathrm{N}_{\text {SERS }}$ is the number of molecules probed in the SERS measurement, estimated as previously discussed for LOD considering the spot area. Thereby, a value of $10^{6}$ was achieved for 
TNT [31]. As they stated, the adsorption chemistry also plays a role in the enhancement mechanism which is not purely based on the electromagnetic effect.

In a following step, it is frequently used the functionalization of substrates in order to improve the interaction between NPs and target analytes. Host molecules, i.e., the molecules applied to functionalize NPs, must possess several features including a strong affinity for both the surface of NPs and the target molecules [33]. Regarding the functionalization of Klarite, Holthoff et al. used xerogel-based molecularly imprinted polymers spun cast on Klarite for the detection of TNT, DNT, and DNB [34, 35]. They noticed that the use of APTES ((3-Aminopropyl)triethoxysilane) favoured the interaction between TNT and xerogel due to the free amine groups from APTES through a strong non-covalent interaction. This functionalized Klarite substrate showed a great stability and reproducibility. LOD was found to be $3 \times 10^{-6} \mathrm{M}$ for TNT [35]. In order to assess the substrate selectivity, the Raman intensities of spectra from TNT, DNT, and DNB solutions at the same concentration were compared, being twice for TNT. As the authors concluded, although the substrate showed affinity for TNT, DNT and DNB, it revealed higher preference for TNT $[34,35]$. Since their major goal was the capability of using this substrate as a reusable SERS sensor, they also studied the analyte removal. Specifically, Holthoff et al. used an ethanol/acetonitrile/acetic acid extraction solution for $24 \mathrm{~h}$ to remove the $80 \%$ of TNT $[34,35]$.

Other typical functionalizations of $\mathrm{Au}$ or Ag NPs have been studied over the last few years for TNT and DNT detection by SERS including the use of cysteine (36), cysteamine (37), PATP (p-aminothiophenol) (38), EHDAB (ethyl-hexadecyl-dimethyl-ammonium bromide) (39), or mono-6-thio-b-cyclodextrin (40). PATP, cysteine, and cysteamine are characterized by having both amino and thiol groups (36-38). According to the authors, the thiol group interacts with $\mathrm{Au}$ or $\mathrm{Ag}$ whereas the amino group interacts with nitro groups from TNT through p-donor-acceptor interactions. Many studies explain this strong interaction by means of the formation of a Meisenheimer complex between TNT and these amino-compounds which improve EF of SERS effect [36, 38, 41, 42]. Figure 2 illustrates the formation of this complex. 


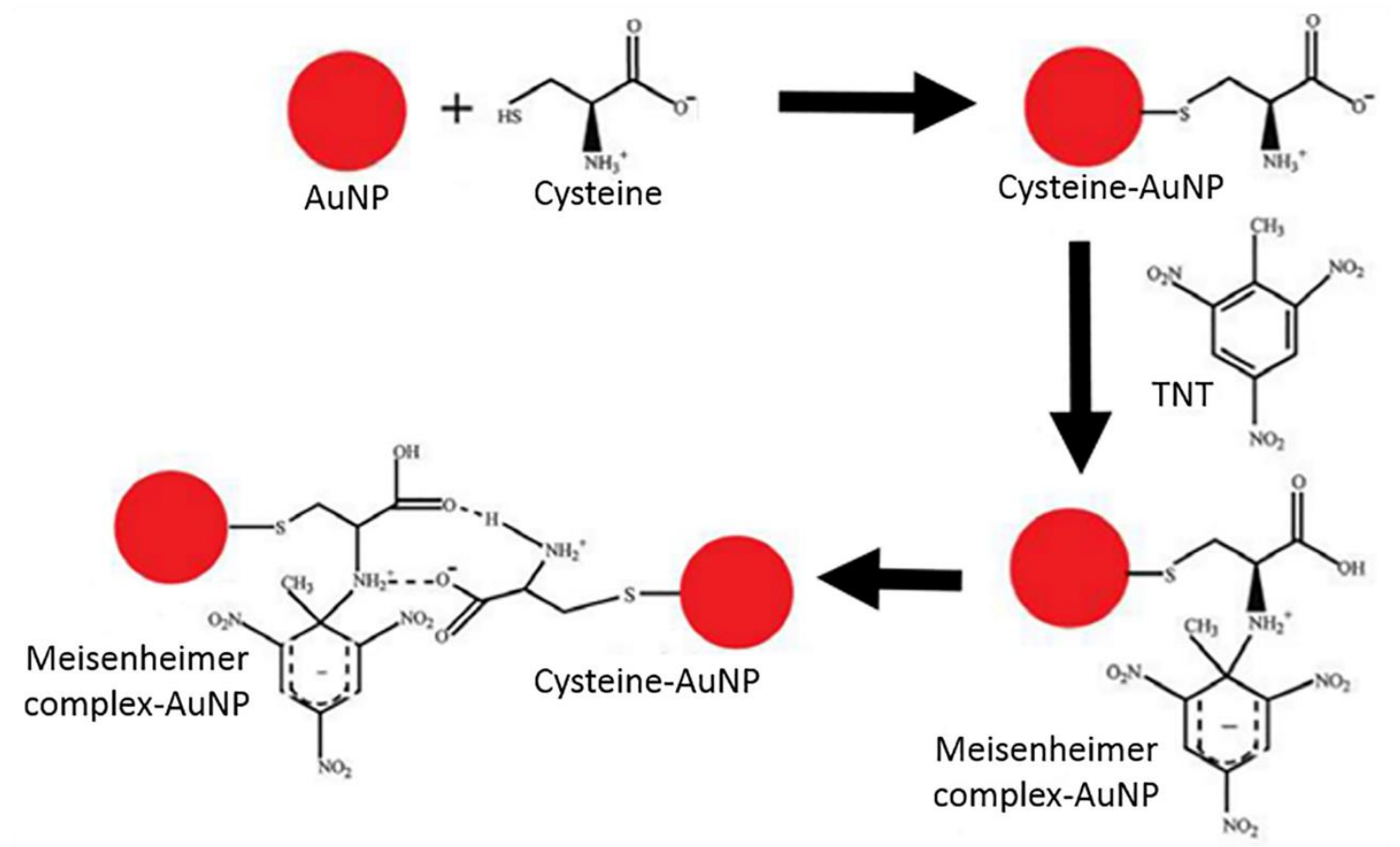

Figure 2. Schematic representation of the formation of Meisenheimer complex between cysteine modified AuNPs and TNT and its possible cross-linking to cysteine-AuNPs. Adapted with permission from Dasary et al. (36).

By using cysteine modified AuNPs, an EF of $10^{9}$ and LOD of $2 \times 10^{-12} \mathrm{M}$ were achieved for TNT [36]. On the other hand, DNT, nitrobenzene, and nitrophenol were not detected by using cysteine, probably due to the no formation of Meisenheimer complex. It is noteworthy to mention that the most intense spectrum was produced by a TNT solution at $5 \times 10^{-9} \mathrm{M}$. Of course, solutions of TNT below $5 \times 10^{-9} \mathrm{M}$ concentration provided less intense spectra, but solutions at 10 and $50 \times 10^{-9} \mathrm{M}$ also did [36]. This result illustrated how important is to find the optimum ratio between analyte and nanoparticles either functionalized or not in order to exploit SERS effect to the maximum. By using cysteamine-coated AgNPs, both TNT and DNT were detected up to $0.05 \mathrm{pg} / \mathrm{mm}^{2}$ which came from $10 \mathrm{~mL}$ of $10^{-4} \mathrm{M}$ solutions [37]. Moreover, the amount of cysteamine was found to be crucial to provide a proper interaction with TNT and DNT and consequently promote SERS effect [37]. An extremely low LOD of $1.5 \times 10^{-17} \mathrm{M}$ was achieved for TNT by using PATP [38]. The detection of TNT by PATP modified AgNPs was accomplished through the detection of TNT-PATP Meisenheimer complex [38]. First, neither TNT nor PATP individually provided significant bands at low concentrations even in presence of AgNPs. On the contrary, the PATP bands became incredibly intense after adding the TNT, and they disappeared some minutes later. According to authors, this is due to the production of the complex that disappeared when the solvent completely evaporated. 
Specifically, TNT was detected by means of the PATP signal increase which was produced by the formation of the TNT-PATP complex. In fact, almost all the characteristic bands of this complex came from PATP except for the band located at 1369 $\mathrm{cm}^{-1}$ which came from TNT, although it was partly overlapped by the PATP band located at $1390 \mathrm{~cm}^{-1}$ [38]. In addition, PATP was also tested for DNT, nitrobenzene, and nitrophenol detection but negative results were achieved for them. Similarly, different thiols were tested for TNT detection including methoxybenzenethiol, mercaptotoluene, and naphthalenethiol but none of them provided so good results as PATP. Thereby the high specificity between TNT and PATP was demonstrated. Finally, a linear correlation between intensity of TNT-PATP bands and TNT concentration was discovered for the range of concentrations $10^{-6} \mathrm{M}-10^{-15} \mathrm{M}$ [38]. Regarding EHDAB-coated AuNPs, an LOD of $10^{-9} \mathrm{M}$ and $10^{-8} \mathrm{M}$ was obtained for TNT and DNT, respectively [39]. Advantageously, bands from EHDAB did not overlap those from TNT or DNT. Interestingly, nitrotoluene and nitrobenzene at $10^{-7} \mathrm{M}$ and nitroethane at $10^{-6} \mathrm{M}$ were also detected by using these EHDAB-AuNPs. Thereby, although EHDAB is not specific for TNT, the spectra of the five compounds were distinguished [39]. Regarding cyclodextrin functionalized AuNPs, a LOD of $10^{-11} \mathrm{M}$ was achieved for DNT [40]. In addition, spherical and triangular AuNPs were tested. The triangular NPs provided an EF of $10^{8}$ for DNT, one order of magnitude over the EF produced by spherical NPs. According to authors, this result is explained by two different aspects. Triangular NPs had their surface plasmonic bands closer to the laser wavelength and their shape also provided an extra enhancement from the molecules attached to the sharp edges and corners. By using these cyclodextrin-AuNPs, a logarithmic correlation was found between the intensity band at $1371 \mathrm{~cm}^{-1}$ and DNT concentration in the range from $10^{-6}$ to $10^{-11} \mathrm{M}$ [40]. Furthermore, picric acid and nitrobenzene were also analysed. Picric acid was not detected but nitrobenzene was. As would be expected, the selectivity between cyclodextrin and analyte was conditioned by both steric and chemical effects. Picric acid was not efficiently captured by cyclodextrin due to the hydrophobic property of the inner cavity thus it was not detected. Only those molecules which were efficiently captured by cyclodextrin such as DNT and nitrobenzene enhanced their SERS spectra [40].

Besides $\mathrm{Au}$ and $\mathrm{Ag}$ nanoparticles, other compounds have been explored as SERS substrates either on its own or in combination with Au/AgNPs, such as titanium dioxide [43-48], silver vanadate and copper [49], silver molybdate [33], alumina [50, 51], nickel 
[52], graphite (single-wall carbon nanotubes) [53], silicon [54], graphene [41, 55], magnetite [56], and zinc oxide [42]. SERS substrates based on titanium dioxide $\left(\mathrm{TiO}_{2}\right)$ were deeply studied by Cruz-Montoya et al. for nitroexplosives SERS detection, mainly TNT and DNT [43-48]. As a summary of all their work, the more relevant results are displayed below. The polymorphism of $\mathrm{TiO}_{2}$ in its rutile or anatase forms was examined in order to test their SERS effect by studying several anatase-rutile mixtures in different proportions. Rutile was found to produce higher Raman EF [43, 44, 46]. TNT and DNT were detected down to $100 \mathrm{pg}$ and $10 \mathrm{ng}$, respectively, by using the optimum rutileanatase mixture, obtaining greater EFs than using AuNPs [43]. $\mathrm{TiO}_{2}$ was compared with $\mathrm{Ag} / \mathrm{Au}$ alloys for TNT detection being Ag/Au alloys with which TNT signal enhanced best [45]. Later studies in which $\mathrm{Ag}, \mathrm{Au}, \mathrm{Ag} / \mathrm{Au}$, and $\mathrm{Ag} / \mathrm{TiO}_{2} \mathrm{NPs}$ were compared for TNT detection, the order of NPs in terms of highest EF was the following: $\mathrm{Ag}>\mathrm{Ag} / \mathrm{Au}$ $>\mathrm{Ag} / \mathrm{TiO}_{2}>\mathrm{Au}[47,48]$. By using Ag NPs, a LOD of $10^{-12} \mathrm{M}$, corresponding to $0.1 \mathrm{fg}$, was achieved for TNT. According to previous studies, $\mathrm{pH}$ was found to affect SERS effect for TNT and DNT, obtaining better results in basic media ( $\mathrm{pH} 10$ and 12, respectively) [47]. $\mathrm{Sc}_{2} \mathrm{O}_{3}$ was also tested and the results were quite similar to $\mathrm{TiO}_{2}$ concluding that the spectra obtained by using oxides to enhance the Raman signal are quite different from ordinary SERS since all vibrations seem to be enhanced by the same factor [45]. In addition, the authors postulated that enhancement depends on the physical form of the oxide: type of polymorph present; bulk, cluster, or nanoparticle present; and oxidation state of the metal cation $[45,48]$.

A SERS-active substrate based on AgNPs produced through a reaction between $b$-silver vanadate nanoribbons and copper foil was tested by Shao et al. for trace detection by analysing four different analytes at very low concentrations [49]. One of these four was TNT, which was detected down to $10^{-15} \mathrm{M}$. In addition, size of the particles was also studied and the smaller AgNPs were the higher enhancement they caused. However, this enhancement was almost the same if they were less than $15 \mathrm{~nm}$ size (i.e., $5 \approx 10 \approx 15 \mathrm{~nm}$ ) [49].

A similar SERS-active substrate based on PATP functionalized AgNPs coated on silver molybdate nanowires were studied by Yang et al. for TNT detection [33]. The selective assembly of TNT was produced through the strong acid-base pairing interaction between the electron-rich amino group of PATP and the electron-deficient aromatic ring of TNT [33]. DNT was also analysed but no SERS effect was observed, which demonstrated its 
worse interaction with PATP. TNT solutions from $10^{-7}$ to $10^{-11} \mathrm{M}$ were analysed and properly detected establishing a LOD of $10^{-12} \mathrm{M}$. A logarithmic correlation between Raman intensity of nitro band at $1359 \mathrm{~cm}^{-1}$ and TNT concentration (I vs. $\log$ (conc)) was found for that concentrations interval [33].

Ko et al. developed an alumina SERS-active substrate based on aligned vertical cylindrical nanocanals decorated with AuNPs for DNT detection [50]. They were functionalized with PDDA (poly(diallyldimethylammonium chloride)) and CTAB (cetyltrimethylammonium bromide) in order to improve both AuNPs immobilization and DNT adsorption. $10 \mathrm{~mL}$ of a 100 ppb DNT solution were analysed being DNT properly identified. Thereby, EF and LOD for DNT were calculated arising $10^{6}$ and $10 \mathrm{fg}$, respectively [50]. In a subsequent study, this substrate was slightly modified by substituting PDDA for PEI (polyethylenimine) and it was tested for TNT, DNT, and HMTD (Hexamethylene triperoxide diamine) molecular detection [51]. DNT and TNT were detected down to 0.1 and $0.05 \mathrm{ppt}$ which corresponded to 10 and $5 \mathrm{zg}$ of DNT and TNT on the substrate which is an equivalent of 30 and 15 molecules within the laser beam. Extremely high EF values of $10^{12}$ and $10^{13}$ were found for DNT and TNT by using this substrate. A preliminary testing of this substrate for vapour detection was also encouraged after demonstrating a LOD for DNT vapour below 100 ppt [51]. Regarding HMTD detection, it was detected down to few ppm corresponding to $1 \mathrm{pg}$ in the laser spot [51].

Hybrid nickel nanostructures were studied by Sajanlal et al. for TNT, DNT, and RDX detection [52]. By carrying out a galvanic displacement reaction, Ni nanowires could be easily transformed to hybrid nanostructures which combined $\mathrm{Ni}$ and a noble metal including $\mathrm{Ni}-\mathrm{Au}$ nanocarpets, Ni-Pd nanotubes, and $\mathrm{Ni}-\mathrm{Ag}$ and $\mathrm{Ni}-\mathrm{Pt}$ nanowires. TNT and DNT were detected down to $10^{-7} \mathrm{M}$ corresponding to an EF value of $10^{6}$ whereas LOD and EF values for RDX were $10^{-6} \mathrm{M}$ and $10^{5}$, respectively [52]. Intensity varied depending on the region of the substrate, a fact which was attributable to the different $\mathrm{Ni} /$ noble metal ratio along the substrate since galvanic displacement reaction was not uniform. Reusability of Ni-Au nanocarpets was tested and good results were achieved along the first five times of usage. Afterward, sensitivity decreased upon further use. The cleaning process between uses involved washing with deionized water followed by gentle sonication with acetone for $1 \mathrm{~min}$ and finally keeping at $300^{\circ} \mathrm{C}$ for $30 \mathrm{~min}$ in a furnace [52]. 
A different hybrid nanostructure based on PATP functionalized AuNPs-decorated singlewall carbon nanotubes was developed and studied by Demeritte et al. for TNT detection [53]. By using these hybrid NPs, TNT was detected down to $10^{-13} \mathrm{M}$ corresponding to an EF of $8 \times 10^{11}$. Interestingly, the same AuNPs without single-wall carbon nanotubes allowed TNT detection down to $4 \times 10^{-12} \mathrm{M}$, one order of magnitude lower. This fact showed the improvement due to the carbon nanotubes. DNT and RDX solutions were also analysed with these hybrid NPs but DNT and RDX were not detected even at $10^{-7} \mathrm{M}$ concentration. According to authors, this result clearly demonstrated that their hybrid NPs were highly selective for TNT [53].

Talian et al. combined separation based on Thin Layer Chromatography through microfluidic channels with SERS detection on a novel black silicon substrate covered with Ag and AuNPs [54]. This procedure was accomplished for DNT and DNB detection. In that work, sensitivity and LODs for analytes were not studied since quite large amounts of DNT and DNB were analysed ( $1 \mathrm{~mL}$ of a 50/50 mixture $0.1 \mathrm{M}$ DNT and 0.1 M DNB). On the contrary, the study was focused on DNT-DNB separation previous to SERS detection in order to facilitate their identification by analysing separately [54]. By using toluene as mobile phase, DNB migrated first followed by DNT. Both were separated along the microchannel and individually detected [54].

PATP functionalized AgNPs placed on graphene oxide nanosheets was the SERS-active substrate that Liu et al. studied for TNT detection [41]. As previously reported [33, 38, 53], the specific interaction between PATP and TNT promotes SERS effect. Liu et al. demonstrated this fact by comparing the results between using PATP functionalized AgNPs and AgNPs without functionalization but both on graphene nanosheets. As expected, TNT was only detected by using the functionalized ones [41]. Concretely, the results were quite similar to those reported by Zhou et al. [38] in which the resulting spectra from PATP-TNT complex were a combination between PATP and TNT bands. In fact, TNT bands were again quite overlapped by the PATP ones. By using graphene nanosheets as support for PATP functionalized AgNPs, a LOD of $5 \times 10^{-16} \mathrm{M}$ was calculated for TNT [41], which was very close to the LOD previously reported by using PATP functionalized AgNPs without graphene $\left(1.5 \times 10^{-17} \mathrm{M}\right)$ [38]. Therefore, the presence of graphene as support does not seem to affect SERS effect neither positively nor negatively. In addition, Liu et al. found a logarithmic correlation between the intensity of a PATP-TNT band and TNT concentration (I vs. $\log (\operatorname{conc})$ ) [41]. Finally, the 
selectivity of this PATP-AgNPs-graphene substrate was studied through the analysis of DNT, nitrobenzene, nitrotoluene, and nitrophenol at $10^{-7} \mathrm{M}$. As a result, their SERS spectra exhibited quite less intensity demonstrating the worse interaction between these molecules and PATP [41].

Graphene oxide has also been used in combination with AuNPs. A hybrid SERS-active substrate based on graphene oxide and gold was evaluated by Kanchanapally et al. for TNT and RDX detection [55]. Concretely, acyl chloride functionalized graphene oxide and cystamine dihydrochloride functionalized AuNPs were used. Interestingly, RDX was analysed by using the hybrid graphene-Au substrate and by using alone AuNPs. The EF values obtained in each case demonstrated the improvement due to graphene oxide since they were $10^{11}$ and $10^{7}$, respectively. Thereby, by using this graphene-Au substrate, LODs achieved for TNT and RDX were $10^{-14} \mathrm{M}$ and $5 \times 10^{-13} \mathrm{M}$, respectively [55].

PATP functionalized magnetite $\left(\mathrm{Fe}_{3} \mathrm{O}_{4}\right)$-Au NPs were studied by Ahmoud et al. as SERS active substrate for trace detection and removal of TNT from water and soil samples [56]. Specifically, APTES and PATP functionalized lignin modified hybrid microspheres, comprising PSA (poly(styrene-co-acrylic acid)), Silica $\left(\mathrm{SiO}_{2}\right)$, magnetite, and AuNPs were synthesized and used for SERS measurements. In that study, like in the previous ones where PATP was used [38, 41], TNT detection was accomplished through the formation of PATP-TNT complex and the identification of its bands. Aminated lignin, a selective absorbent of TNT, was used in order to increase the LOD and selectivity, which was necessary for TNT removal. The advantage of using lignin was demonstrated by comparing the LODs achieved for TNT with and without lignin. When lignin was present, TNT was detected down to $7 \times 10^{-13} \mathrm{M}$ in water samples and $2 \times 10^{-12} \mathrm{M}$ in soil samples whereas $10^{-10} \mathrm{M}$ was the lowest concentration detected for TNT without using lignin for both water and soil samples [56]. In addition, after analysing soil samples by mixing 300 $\mathrm{mg}$ of the contaminated soil with $1 \mathrm{mg}$ of these lignin modified PSA/SiO $2 / \mathrm{Fe}_{3} \mathrm{O}_{4} / \mathrm{AuNPs}$, $85 \%$ of TNT was removed from the soil. On the contrary, only $55 \%$ of TNT was removed by using $\mathrm{PSA} / \mathrm{SiO}_{2} / \mathrm{Fe}_{3} \mathrm{O}^{4} / \mathrm{AuNPs}$ without lignin. Finally, the reusability of microspheres was investigated by desorbing TNT with ethanol. Interestingly, ethanol was quite efficient for TNT removal from lignin [56].

Zinc oxide $(\mathrm{ZnO})$ has also been investigated for SERS detection of TNT. Specifically, PATP functionalized $\mathrm{ZnO}-\mathrm{Ag}$ hybrid nanoflowers were studied by $\mathrm{He}$ et al. for this aim [42]. Once more, the detection of TNT was accomplished through the identification of 
PATP-TNT complex, like in preceding studies $[38,41,56]$ previously discussed. By using $\mathrm{ZnO}-\mathrm{Ag}$ hybrids, TNT solutions at different concentrations from $10^{-5} \mathrm{M}$ to $5 \times 10^{-}$ ${ }^{9} \mathrm{M}$ were analysed. In all of them, TNT was properly detected. In addition, a logarithmic correlation between the intensity of the specific TNT band at $1430 \mathrm{~cm}^{-1}$ and TNT concentration was established (I vs $\log$ (conc)) for that range of concentrations [42]. Once more, selectivity of the substrate was investigated by analysing other explosives. In this case, they were picric acid, DNT, and nitrotoluene. All of them provided quite weaker SERS enhancements than TNT provided. However, the number of nitro groups contained in the molecule seemed to affect to a certain extent the enhancement, as results showed: picric acid > DNT > nitrotoluene [42].

Other effective ways to improve the sensitivity and LODs of TNT by SERS involve the selective functionalization of TNT in order to facilitate its efficient adsorption on Ag or Au surfaces. Different chemical procedures have been developed to functionalize TNT for its detection by SERS, most of them based on the formation of TNT derived azo dyes. For example, McHugh et al. researched the detection of TNT by SERS through the reduction of TNT to 2-amino-4,6-dinitrotoluene followed by the diazo coupling with different coupling reagents $[57,58]$. According to the authors, among the amine, pyridine, $1 \mathrm{H}$-benzotriazole and quinoline derivatives which were tested, 8-hydroxiquinoline was the best coupling agent in terms of ease of synthesis and efficiency of SERRS [57]. The detection of TNT dye was carried out through microfluidics and using $514.5 \mathrm{~nm}$ excitation. In microfluidics, colloid, analyte and aggregating agent were pumped together into a flow cell and mixed. The signal was measured from the flowing stream when passed through the laser beam. By using a silver colloid, TNT was detected down to $10^{-14} \mathrm{~mol}$, corresponding to $10 \mathrm{~mL}$ of a $10^{-9} \mathrm{M}$ TNT solution $[57,58]$.

A derivatization of TNT into sulfonated TNT $\left(\mathrm{TNT}-\mathrm{SO}_{3}\right)$ was investigated together with cetylpyridinium chloride functionalized AgNPs by Liu et al. [59]. These particular TNT derivatization and AgNPs functionalization were used to enhance the TNT signal by the SERRS effect due to the formation of the coloured cetylpiridinium-TNT- $\mathrm{SO}_{3}$ complex containing the chromophore. By using these functionalized AgNPs, the sulfonated TNT was detected down to $5 \times 10^{-11} \mathrm{M}$. In addition, reproducibility of the substrate was evaluated by studying the variation of the intensity among sequential measurements of TNT solutions at different concentrations. Results demonstrated that from $10^{-7} \mathrm{M}$ to $10^{-}$ 
${ }^{10} \mathrm{M}$, intensity variation increased from $15 \%$ to more than $20 \%$. Nevertheless, the fingerprint bands of TNT were always clearly distinguished [59].

However, derivatization methods cannot be considered as non-destructive procedures. They transform the analyte so exactly the same evidence is not further available after the analysis. Therefore, this fact avoids talking about a non-destructive spectroscopic approach.

RDX, HMX, PETN, and other military and commercial explosives

Besides TNT and DNT, other military explosives and precursors have started to be investigated by SERS including RDX [26, 28-32, 44, 52, 55, 60], HMX [26], NG [27, 28], tetryl [28], PETN [29-31], EGDN [29, 30], $\mathrm{KNO}_{3}$ [31], DNAN [61], NTO [62], and HNIW [24].

Regarding RDX detection, almost all the studies have been previously reviewed since TNT detection was also pursued in them. However, the specific data relating to RDX have been selected and displayed below.

Commercial klarite substrate [26, 28-32] used by Botti et al. was also tested for RDX detection, as well as $\mathrm{TiO}_{2}$ substrate from Cruz-Montoya et al. [44], hybrid Ni-Au NPs from Sajanlal et al. [52], and graphene oxide-AuNPs used by Kanchanapally et al. [55]. In addition, a new study in which colloidal AuNPs were investigated for independent RDX detection was also found [60]. As an essential summary, by using Klarite, RDX was detected down to a concentration of 100 ppm [26] in a first attempt, a mass of $200 \mathrm{pg}$ in laser spot [29] few years later, $80 \mathrm{pg}$ [30] the following year and down to $20 \mathrm{pg}$ [32] the following one. This improvement was achieved by using klarite substrates with different dimensions of their inverted pyramids. Therefore, the structural features of SERS active substrates also seem to affect to a certain extent the SERS enhancement. With regard to the other SERS active substrates, it is important to highlight that LODs achieved for RDX were $10^{-6} \mathrm{M}$ either by using Ni-Au NPs [52] or only AuNPs [60] and $5 \times 10^{-13} \mathrm{M}$ by using the acyl chloride functionalized graphene oxide-cystamine dihydrochloride functionalized AuNPs [55], which represents the best LOD for RDX so far in every technique. The EF obtained in this case for RDX was $10^{11}$ [55], much larger than the usual $10^{5}-10^{6}$ reported for other substrates $[26,31,52,60]$. Interestingly, the study carried 
out by Hatab et al. by using colloidal AuNPs [60] was focused on RDX quantification in real water samples. According to authors, the intensity variation of the characteristic band at $874 \mathrm{~cm}^{-1}$ from RDX was linear correlated with RDX concentration [60]. The analysis of the real water sample was performed through the standard addition method. Specifically, $15 \mathrm{~mL}$ of a groundwater sample (with an unknown concentration of RDX) were spiked with $0,50,70,175$, and $300 \mathrm{~mL}$ of a stock solution of RDX (at $177.7 \mathrm{mg} / \mathrm{L}$ ) and the intensity of the band at $874 \mathrm{~cm}^{-1}$ was measured in each solution. Thereby, the unknown RDX concentration was determined by SERS as $0.15 \pm 0.12 \mathrm{mg} / \mathrm{L}$, which was a quite accurate and precise result considering that the result obtained by HPLC (USEPA Method 8330) was $0.12 \pm 0.4 \mathrm{mg} / \mathrm{L}$ [60].

The unique study in which HMX was analyzed by SERS was accomplished by using Klarite substrate [26]. As result, a LOD of 100 ppm was achieved for HMX corresponding to an EF value of $10^{6}$.

NG, tetryl, PETN, EGDN, and $\mathrm{KNO}_{3}$ were also analyzed by using Klarite substrate [2731]. Among the most relevant results, the knowledge of their spectral fingerprints is, undoubtedly, extremely useful. Regarding sensitivity studies, it is important to mention that NG, PETN, and EGDN were detected down to 8 pg [28], 5 pg [30, 31], and $30 \mathrm{pg}$ [30] in laser spot, respectively. In addition, an EF of $3.6 \times 10^{3}$ was achieved for $\mathrm{KNO}_{3}$ by using Klarite substrate [31].

Interestingly, one of those studies was focused on the differentiation and identification of TNT, RDX, PETN, and EGDN by SERS supported by chemometrics [30]. Specifically, a PCA (Principal Component Analysis) including 67 samples from the four explosives (around 16 samples per explosive) was performed. According to Figure 3, results demonstrated enough separation among the four explosives to differentiate them [30]. In fact, that separation was already evident by considering PC1 and PC2, which explained $63 \%$ of the model. When PC1, PC2, and PC3 were used together, the separation of explosives was obviously improved and the model explicability increased up to $76 \%$ [30]. Even though PCA is an exploratory data analysis tool and, therefore, subsequent chemometric methods for classification need to be performed, the preliminary results achieved by PCA encourage to continue this research. 


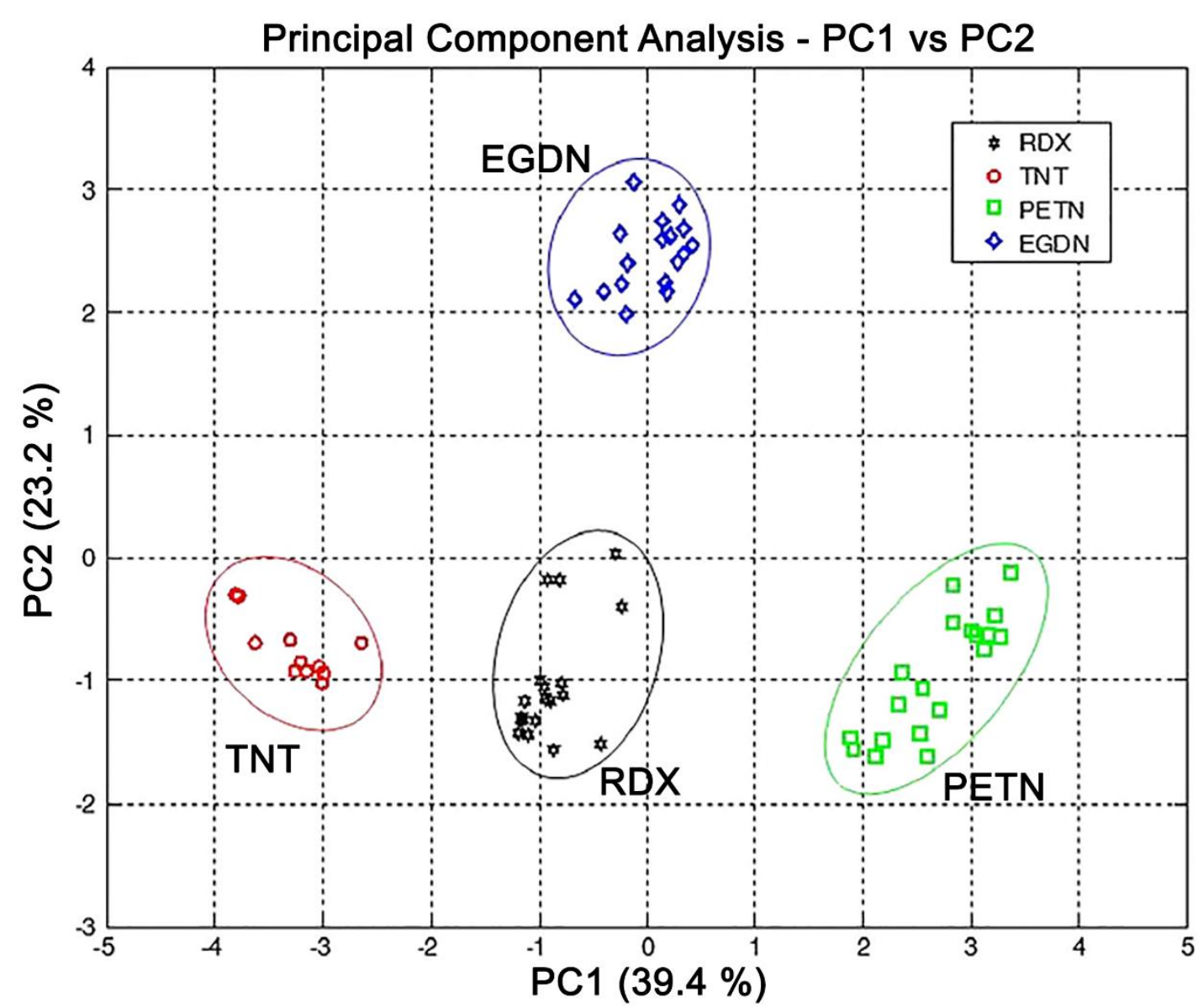

Figure 3. A PCA 2D score plot of PC1 vs PC2 for the SERS and Raman spectra dataset. Numbers in parentheses on each axis represent the percentage variance that each principal component accounts for. Adapted with permission from Botti et al. [30].

DNAN explosive was investigated by $\mathrm{Xu}$ et al. using L-cysteine methyl ester hydrochloride- functionalized AgNPs due to DNAN increasing usage as replacement for TNT [61]. By using these modified AgNPs, DNAN was detected down to $20 \mathrm{mg} / \mathrm{L}$ (or $0.2 \mathrm{ng}$ ) and $0.1 \mathrm{mg} / \mathrm{L}$ (or $1 \mathrm{ng}$ ) in deionized water and aged tap water, respectively. That corresponded to an $\mathrm{EF}$ value of $1.4 \times 10^{8}$. Interestingly, a linear correlation between DNAN concentration and intensity of $830 \mathrm{~cm}^{-1}$ band was found along the concentration range studied (0.02-10 mg/L). According to the authors, the formation of a Meisenheimer complex between DNAN and L-cysteine methyl ester hydrochloride functionalized AgNPs promoted the enhancement. In fact, DNAN at $100 \mathrm{mg} / \mathrm{L}$ was not detected when non-functionalized AgNPs were used [61]. In addition, other three chemicals (L-cysteine, $\mathrm{N}$-acetyl-L-cysteine, and L-cysteine ethyl ester hydrochloride) were tested for AgNPs functionalization in order to check the interaction with DNAN. The effect of different anions and cations usually present in water was also studied. As results demonstrated, $\mathrm{CO}_{3}{ }^{2-}, \mathrm{Cl}^{-}$, and $\mathrm{K}^{+}$ions did not affect the SERS analysis of DNAN whereas $\mathrm{SO}_{4}{ }^{2-}, \mathrm{Na}^{+}$, 
$\mathrm{Mg}^{2+}$ and $\mathrm{Ca}^{2+}$ ions significantly quenched it. Fortunately, the negative effect of bivalent cations could be offset by $\mathrm{SO}_{4}{ }^{2-}$ anion [61].

$\mathrm{Xu}$ et al. also investigated the detection of NTO explosive. An Ag nanofilm which included silicates, ammonia, $\mathrm{Na}^{+}, \mathrm{Ag}^{0}, \mathrm{PO}_{4}{ }^{3-}$, and hydrocarbons (glucose and its oxidized derivatives) on its surface was used as SERS active substrate for NTO detection [62]. Thereby, NTO was detected down to $35 \mathrm{mg} / \mathrm{L}(0.35 \mathrm{ng})$ and $350 \mathrm{mg} / \mathrm{L}(3.5 \mathrm{ng})$ in deionized water and aged tap water, respectively. An EF of $3.6 \times 10^{7}$ was achieved for NTO in deionized water. Although the correlation between the SERS intensity of NTO bands at 1387, 1309, and $846 \mathrm{~cm}^{-1}$ and NTO concentration was not linear, their log-log relationships were. Interestingly, the selectivity of that substrate for NTO was demonstrated since neither TNT, RDX, nor DNAN were detected at $100 \mathrm{mg} / \mathrm{L}$ [62]. Authors suggested that selectivity could be attributed to the heterocyclic ring of NTO which promoted its adsorption onto the surface of $\mathrm{Ag}$ nanofilm. In addition, the effect of $\mathrm{pH}$ on NTO detection was studied. According to results, NTO was always detected between 4.7 and 9.1 even though $\mathrm{pH}$ varied the relative intensity among bands. As in their previous study with DNAN, the effect of different ions on NTO SERS detection was examined too. In this case, neither $\mathrm{Na}^{+}, \mathrm{K}^{+}, \mathrm{Mg}^{2+}, \mathrm{Ca}^{2+}, \mathrm{SO}_{4}{ }^{2-}, \mathrm{CO}_{3}{ }^{2-}$ nor $\mathrm{NO}^{-}$affected the detection of NTO at $3.5 \mathrm{mg} / \mathrm{L}$. On the contrary, the presence of $\mathrm{Cl}^{-}$sometimes improved whereas sometimes hindered the NTO detection. According to authors, it depended on $\mathrm{Cl}^{-}$concentration and/or the time since $\mathrm{Cl}^{-}$addition and SERS analysis [62].

Finally, HNIW, also known as CL-20, was studied by SERS by using the biosynthesized AgNPs previously expounded for TNT detection [24]. As previously mentioned, by using these bio-AgNPs, HNIW was detected down to $4 \times 10^{-10} \mathrm{M}$ and showed an EF of $10^{8}$ for clove-reduced AgNPs and $10^{6}$ for pepper-reduced AgNPs [24].

\section{TATP and HMTD}

Finally, peroxide explosives such as TATP and HMTD have called the attention due to their increasing use in IEDs lately [1]. They constitute a great threat since the difficulties related to their identification due to the absence of nitro groups in their structures and their volatility and instability. Particularly, their instability makes the analysis of peroxide explosives a difficult task by IR and Raman spectroscopy [63]. It may be the reason why 
peroxide explosives have been quite less researched by spectroscopic techniques in general and by SERS spectroscopy in particular.

TATP in solution was only studied by SERS by using Klarite substrate [27, 28]. It was detected down to $400 \mathrm{pg}$ in laser spot, resulted of placing $0.1 \mathrm{~mL}$ of a solution at 0.1 $\mathrm{mg} / \mathrm{mL}$ onto the klarite substrate. Due to its volatility and instability, TATP spectra from those small amounts of TATP displayed too much noise [27, 28]. Although TATP in solution has not been deeply researched by SERS, it has been studied in vapour phase as it is summarized below.

Regarding HMTD, it was preliminary studied by using the alumina-PEI-CTAB-AuNPs substrate developed by Ko et al. for TNT and DNT detection [51]. As previously mentioned, HMTD was detected down to $1 \mathrm{pg}$ in laser spot (few ppm) by using that substrate, although TNT and DNT had been detected down to 5 and $10 \mathrm{zg}$, respectively. However, some spectral differences were observed for certain bands, which seemed to indicate that HMTD underwent some kind of decomposition [51]. That was deeper researched in a subsequent study in which HMTD was photo-decomposed on purpose [64]. Interestingly, the bands that appeared after decomposition coincided with the unknown bands previously observed. HMTD was now detected down to 2 pg (3 ppm) from its decomposition products which included $\mathrm{CO}, \mathrm{HCN}, \mathrm{HNCO}, \mathrm{CH}_{4}, \mathrm{CH}_{2} \mathrm{O}$, and $\mathrm{NH}_{2} \mathrm{CO}$. As authors stated, the HMTD detection was achieved through the detection of its photocatalyzed decomposition products since the presence of $\mathrm{C}-\mathrm{NH}, \mathrm{CH}_{2} \mathrm{O}$, and $\mathrm{NH}_{2} \mathrm{CO}$ fragments could only be generated by the $\mathrm{O}-\mathrm{O}$ and $\mathrm{C}-\mathrm{N}$ bond cleavage of HMTD molecules [64]. Certainly, some other peroxide compounds containing also a C-N bond could undergo a similar photodecomposition process. In any case, this method is destructive which makes impossible to keep the evidence after the analysis.

\section{Chemical noses based on SERS as sensors for explosive vapours detection}

The difficult task of using SERS for explosive vapour detection has also been occasionally investigated for the last two decades. It is important to highlight that TNT and DNT vapours have been again the two explosive vapours most studied [18, 23, 51, 65-77], followed by TATP vapour [69, 70, 78, 79]. The analysis of explosive vapours by SERS started to be researched around 1998 by Haas et al. [18], a few years after Kneipp et al. [17], published their study about the detection of TNT in solution by SERS. Haas et 
al. focused on the detection and identification of TNT and DNT vapours. First, they wondered about the most suitable SERS substrate for vapour detection. Particularly, Au foil vs. colloidal AuNPs were studied [18]. According to the authors, AuNPs provided the best sensitivity in terms of concentration of analyte solution that can be detected. However, in terms of mass of analyte that can be detected in the focal spot, both substrates were comparable. In fact, when analysing vapours it is the mass of analyte what is relevant [18]. In addition, as the authors stated, the use of colloids in a vapour sensor would have many disadvantages including longer sampling and detection periods, and instability of the colloids over time [18]. That is the reason why Au foil was selected for vapour detection. In that preliminary study, DNT vapour which emanated from bulk DNT at room temperature was detected. Afterwards, subsequent studies directed towards the aim of landmine detection were accomplished by this group [65-68]. Specifically, TNT [6568], DNT [65-68], DNB [65, 67], 4-NH2-2,6-DNT [65], RDX [68], HMX [68], PETN [68], and TATB [68] were the all explosive compounds which they studied. Since 2,4DNT is the main compound of the vapours that emanate from TNT [66, 67], major research was done for the detection of DNT. Less than $10 \mathrm{pg}$ of DNT vapour from headspace above a $46 \mathrm{mg} / \mathrm{L}$ DNT solution was detected [65]. In fact, at $19^{\circ} \mathrm{C}$, the headspace DNT concentration was lower than $1 \mathrm{ppb}$ [65]. On the contrary, TNT signals were observed only at temperatures above $25^{\circ} \mathrm{C}$ due to the low vapour pressure of TNT [65]. Preliminary studies focused on the use of a portable SERS sensor for real on field landmine detection were accomplished by analysing the air above different anti-tank and anti-personnel landmines that had been buried 45 days before. Although results were not conclusive due to the low signal-to-noise ratio in SERS spectra, the nitro band was visible [65]. SERS substrate was subsequently improved by washing it with a $0.01 \mathrm{M} \mathrm{NaOH}$ solution $[66,67]$. Thereby, EF improved one order of magnitude. According to authors, this offered two advantages: greater adsorption from TNT and DNT anions and the potential for greater SERS enhancement. Interestingly, vapour detection of DNT was detected from both aqueous solutions and soil samples down to 10 and $5 \mathrm{ppb}$, respectively, even though some of the aqueous solutions were spiked with an acetone impurity and some of the soil samples were spiked with diesel fuel, both used as potential chemical interferences $[66,67]$. Moreover, a curve fitting program was designed for data analysis of the nitro band at $1350 \mathrm{~cm}^{-1}$ in order to identify whether a sample was contaminated with DNT or not [67]. Results were right for many of the samples but there were some false negatives among the most diluted samples. For that reason, PCA 
procedure was also explored for data analysis. By using PCA, all the samples were rightly identified except for one of the samples contaminated with acetone [67]. Finally, this group also studied vapours from other relevant explosives by SERS including RDX, HMX, PETN, and TATB [68]. Although TNT and DNT vapours were detected down to $1 \mathrm{ppb}$, corresponding to $100 \mathrm{fg}$, the rest of explosives did not undergo such EF. Particularly, RDX, HMX, and TATB were detected down to $1 \mathrm{pg}$. Regarding PETN, the analysis of $10 \mathrm{pg}$ of PETN enabled to estimate an LOD of $1 \mathrm{pg}$ for PETN [68].

DNT vapour at $1 \mathrm{ppb}$ was also detected by using colloidal AgNPs inside a microfluidic based device developed by Piorek et al. [74]. According to Figure 4, DNT molecules (red spheres) diffused from the gas phase into the liquid phase (red arrows) where AgNPs (white spheres) were suspended. The first spectral signal due to DNT appeared after 2 min of DNT vapour passing through the microchannel and it reached the maximum intensity after $6.5 \mathrm{~min}$. According to the authors, the greatest advantage of these microfluidic based devices lied in the fact that SERS substrate was continuously refreshed [74].

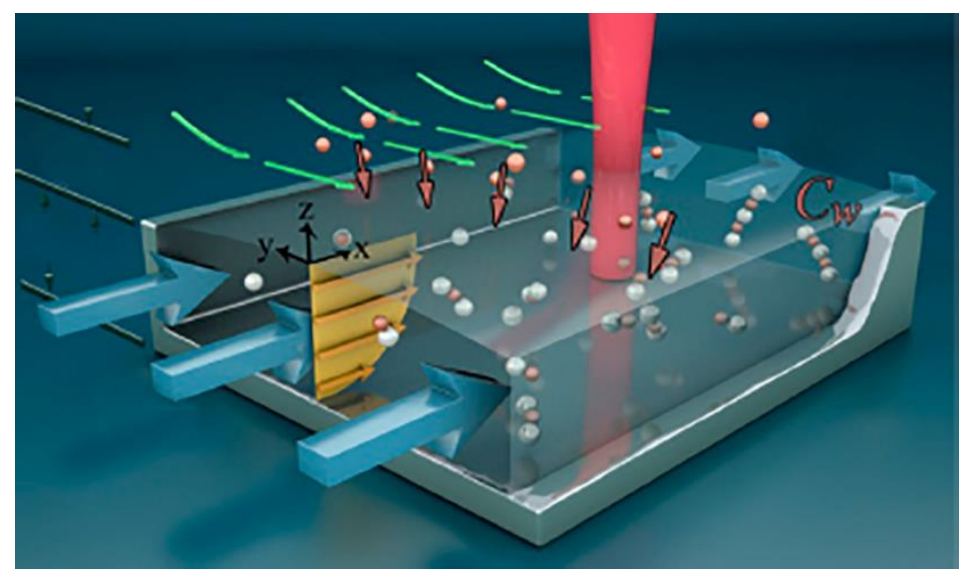

Figure 4. Illustration of the free-surface microfluidic channel in which the aqueous microfluidic phase flows from left to right (blue arrows). Adapted with permission from Piorek et al. (74).

Wang et al. achieved the detection of DNT vapor down to $10 \mathrm{ppt}$ by using nanoparticle cluster arrays made of gold-coated PMMA (poly(methyl methacrylate)) [72]. In order to improve the adsorption of DNT, the substrate was previously washed with a solution of $\mathrm{NaOH}$. The optimum time for DNT adsorption was found to be $5 \mathrm{~min}$. DNT signal started to decrease after that time because the $\mathrm{NaOH}$ solution on the substrate, which promoted the adsorption of DNT, started to evaporate. Vapour of DNT was generated by incubating an aqueous solution of DNT of known concentration in a closed glass chamber at $25^{\circ} \mathrm{C}$ 
overnight [72]. A concentration range from $100 \mathrm{ppb}$ to $10 \mathrm{ppt}$ in vapour phase was studied. In addition, a fertilizer, a pesticide, and a diesel fuel samples were tested as potential interferent vapours. None of them displayed a similar spectrum to that from DNT. However, in combination with these interferent vapours it was observed that the intensity of DNT signal was a bit lower than it was on its own. That fact might indicate that those interferent vapours were also adsorbed on the substrate displacing some of the DNT molecules. Despite that circumstance, DNT at $10 \mathrm{ppt}$ was still detected [72].

Oo et al. accomplished the detection of DNT vapour by using AuNPs synthesized using an UV-assisted photo-chemical reduction method and subsequently formed a monolayer on the glass slide through polymer-mediated self-assembly [73]. AuNPs with different sizes were tested. The bigger ones (117 $\mathrm{nm}$ diameter) provided the best results. After 1 min of adsorption, DNT signal was already clearly visible. A LOD of $0.4 \mathrm{ag}$, which corresponds to a sub-ppb DNT concentration in air, was estimated for DNT. In addition, the EF for DNT vapour was found to be $5 \times 10^{6}$ with those AuNPs [73].

Commercial Klarite substrate has also been repeatedly used for explosive vapour detection [69-71, 76, 78].

Fang et al. studied the adsorption of TATP vapour onto Klarite substrate [78]. Analysis at different temperatures (from $25-85^{\circ} \mathrm{C}$ ) were tested and different times of adsorption (from 5- $40 \mathrm{~s}$ ) were also studied. Results demonstrated that TATP signal increased with temperature up to $65^{\circ} \mathrm{C}$ and then it kept constant. The same applied to time of adsorption where TATP signal increased for the first $20 \mathrm{~s}$ and then it kept constant [78]. According to the authors, for a fixed exposure time, large amounts of TATP vapour due to higher temperatures produce multiple layers on the substrate which saturates. With regard to time, for a fixed temperature, longer times of adsorption of TATP vapour saturates the substrate too. Interestingly, by fixing $35^{\circ} \mathrm{C}$ and $20 \mathrm{~s}$ of adsorption time, an LOD of 0.02 $\mathrm{mg} / \mathrm{L}$ was achieved for TATP [78].

Wackerbarth et al. developed a device for the detection of airborne explosives based on re-sublimation of the explosive vapours on cooled Klarite substrate [69, 70]. They focused on the detection of TNT and TATP at different temperatures. A demonstration where TNT vapour was detected by re-sublimating it on Klarite substrate at $-20^{\circ} \mathrm{C}$ proved the workability of the device [70]. It was further tested by analysing TATP vapour. Since TATP has a higher vapour pressure, TATP vapour could be detected even at $-73^{\circ} \mathrm{C}$. 
Furthermore, according to authors, the reason why TATP vapour was not detected at lower temperatures could be that contaminants and water from air displaced the TATP from the surface of the SERS substrate since they did not performed the experiments under ultrahigh-vacuum conditions [70].

Afterwards, Wackerbarth et al. studied the capability of SERS to differentiate between explosives and chemicals which though they were not explosives could be potentially mistaken [71, 76]. Specifically, musk xylene and musk ketone (which are present in perfumes) were investigated because of their similar chemical structure to TNT. After all, they are nitroaromatic compounds like TNT. Interestingly, results confirmed that their differentiation was possible by comparing their SERS spectra. In fact, although the spectra were similar, there were enough characteristic differences to identify them. Those spectral differences involved differences in both wavenumber values and relative intensity of bands from nitro groups and aromatic ring, and, of course, some bands which were exclusive for each compound [71]. This study clearly demonstrated the selectivity of SERS technique also with compounds in vapour phase since three extremely similar compounds were differentiated according to their spectral signature. In a subsequent study, that differentiation was supported by PCA where there were three separate clusters which corresponded to the three compounds [76]. In addition, an LOD of $44 \mathrm{pg}$ was measured for musk ketone [76].

TATP vapour was also studied by Spencer et al. by using a silver oxide SERS sensor [79]. At room temperature TATP vapour was not detected. According to the authors, TATP degraded rapidly to acetone and peroxide components. That is the reason why TATP is more easily detected at low temperatures. However, a portable sensor which works on field at room temperature is desired. Spencer et al. studied the possibility of stabilizing TATP vapour by a special coating [79]. Thereby, TATP at room temperature was now detected. Interestingly, TATP signal appeared immediately and no increment was observed in the intensity over time. That clearly demonstrated the efficacy of the adsorption of TATP molecules onto the sensor. In addition, naphthalene and toluene were studied as potential interferent vapours in combination with TATP vapour. Results showed that although the final spectrum had more noise, TATP bands was still clearly visible. According to the authors, that was because sensor had been optimized for oxygen adsorption rather than aromatic adsorption [79]. Interestingly, the sensor was also placed 
in the kitchen and no aroma from food prevented the detection of TATP when the sensor was subsequently exposed to TATP vapours [79].

An Au-coated sapphire substrate was tested by Chou et al. for SERS detection of some nitroaromatic explosives vapours including DNT, 2,4-dinitrochlorobenzene (DNCB), pnitroaniline and nitrobenzene [75]. They were detected at their respective equilibrium vapour concentration at ambient temperature, i.e., $20 \mathrm{ppm}$ for DNT, $11 \mathrm{ppm}$ for DNCB, $28 \mathrm{ppm}$ for p-nitroaniline, and $1813 \mathrm{ppm}$ for nitrobenzene. By comparing their spectra, it was possible to differentiate them by their different characteristic bands even though the all four had the band due to nitro group in common, which was located at $1350 \mathrm{~cm}^{-1}$. The spot-to-spot reproducibility of substrate was checked by accomplishing a mapping, where the standard deviation from ten random spots was below 8\% [75]. According to the authors, this sapphire substrate could be reused after removing old Au coating with aqua regia and recoating with fresh gold. This was demonstrated by reusing the same substrate 5 times for the detection of DNT vapour. The five measures provided a standard deviation of $4 \%[75]$.

PATP functionalized AgNPs on paper were examined for TNT vapour detection through the formation of PATP-TNT Meisenheimer complex [77]. As it had been previously reported in literature $[38,41]$ and previously reviewed in this revision, TNT can be detected by means of the detection of the PATP-TNT complex. Thereby, a LOD of $1.1 \times$ $10^{-14} \mathrm{M}$ was calculated for TNT vapour, corresponding to $16 \mathrm{ag}$ of TNT per $\mathrm{cm}^{2}$ of substrate [77]. TNT vapour from TNT crystals were detected at a distance of $5 \mathrm{~cm}$ corresponding to $10 \mathrm{ppt}$. In addition, DNT, toluene, nitrophenol, and nitrobenzene at $10^{-}$ ${ }^{6} \mathrm{M}$ were also studied but none of them was detected by this substrate, which demonstrated the selectivity of PATP for TNT. Finally, samples which consisted of TNT residues in various matrices such as leather, clothing, envelope, and soil, were analysed and TNT was detected through the TNT vapour that emanated from them. Interestingly, TNT vapour was easily detected $1 \mathrm{~cm}$ far from samples after $2 \mathrm{~s}$. TNT concentration in these matrices was $2.9 \mathrm{ng} / \mathrm{cm}^{2}$ TNT on leather, $7.2 \mathrm{ng} / \mathrm{cm}^{2} \mathrm{TNT}$ on clothing, $5.7 \mathrm{ng} / \mathrm{cm}^{2}$ on the envelope, and $1.4 \mathrm{ppm}$ TNT in soil [77].

Finally, some of the studies reviewed in previous section, which were mainly focused on the detection of explosives in solution, also dealt with the detection of explosives vapours. For example, Ko et al. tested their alumina SERS-active substrate for DNT vapour 
detection too, achieving an LOD of $100 \mathrm{ppt}$ [51]. Zhang et al. also analysed TNT vapour (about $10 \mathrm{mg} / \mathrm{L}$ ) by using their AgNPs prepared through microwave heating method [23].

\section{Detection of perchlorate anion contaminant by SERS}

Perchlorate anion has also been repeatedly studied by SERS since it was first detected by Niaura et al. by using a $\mathrm{Cu}$-roughened electrode [80]. After finding $\mathrm{ClO}_{4}{ }^{-}$physisorbed at $\mathrm{Cu}$ electrode, its characteristic Raman band, which was located at $929 \mathrm{~cm}^{-1}$, enabled the straightforward identification of $\mathrm{ClO}_{4}^{-}[80]$.

Perchlorate anion $\left(\mathrm{ClO}_{4}^{-}\right)$is a widespread environmental contaminant in groundwater and surface water that disrupts thyroid function by competitive inhibition of iodide [81-83]. Due to the high solubility of $\mathrm{ClO}_{4}{ }^{-}$in water and its stability in the environment, $\mathrm{ClO}_{4}{ }^{-}$ contamination is known to extend very large regions $[82,83]$.

Mosier-Boss et al. studied different anions (including $\mathrm{ClO}_{4}^{-}$) by using cationic-coated SERS substrates [81]. $\mathrm{ClO}_{4}{ }^{-}$solutions were detected down to few ppm. Interestingly, at low anion concentration, the anion peak area increased linearly with concentration. However, it did not at higher anion concentrations because adsorption sites on substrate became fully occupied. In addition, the selectivity of substrates towards the anions was examined. Results demonstrated that the strength of interaction was stronger for those ions that exhibited a higher charge, smaller solvated radius, and greater polarizability. In those cases, when several anions were competing for the substrate, quantitative analysis were difficult to achieve since the adsorption sites from substrate were shared among the different anions and therefore SERS intensity due to each anion was lower. Moreover, this became extremely complex in the presence of non-Raman active anions such as $\mathrm{Cl}^{-}$ where no bands were observed due to $\mathrm{Cl}^{-}$but it did occupy part of the substrate [81].

$\mathrm{Gu}$ et al. led the research of $\mathrm{ClO}_{4}{ }^{-}$detection by SERS [82-86]. A large variety of SERS active substrates were tested for $\mathrm{ClO}_{4}^{-}$detection by this group including AgNPs [82], selective bifunctional anion-exchange resins consisting of quaternary ammonium functional groups [82], sol-gel-based substrates based on silane coupling agents and AgNPs [83], cystamine-modified AuNPs [84], Au-silica NPs [85], and DMAE-Au NPs (2-dimethylaminoethanethiol hydrochloride) [86]. Regarding $\mathrm{LOD}, \mathrm{ClO}_{4}{ }^{-}$was detected down to $10^{-6}-10^{-7} \mathrm{M}$ for every substrate [82-85] except for DMAE-Au NPs where LOD 
for $\mathrm{ClO}_{4}^{-}$was improved down to $10^{-9} \mathrm{M}$ [86]. Reproducibility of substrates was also studied. Particularly, the poor reproducibility found for AgNPs [82] was overcome by using any of the other substrates where reproducibility was demonstrated by either achieving the $\mathrm{ClO}_{4}{ }^{-}$signal at all spots which were measured $[82,84,86]$ or showing the high probability of detecting $\mathrm{ClO}_{4}^{-}$at low concentrations [83, 85]. According to the authors, it is a need that SERS-active substrates promote the uniform adsorption of the analyte along substrate because otherwise the probability of finding the analyte becomes extremely low and dependent on where the analyte sits on metal surfaces. This is especially crucial at low concentrations of analyte [84]. Selectivity was also examined in some of the studies by analysing other typical anions such as $\mathrm{SO}_{4}{ }^{2-}, \mathrm{PO}_{4}{ }^{3-}, \mathrm{Cl}^{-}, \mathrm{NO}_{3}{ }^{-}$, and $\mathrm{CO}_{3}{ }^{2-}$ [84-86]. Interestingly, none of them could be misidentified as $\mathrm{ClO}_{4}{ }^{-}$due to their different characteristic Raman bands. However, it was observed that intensity of $\mathrm{ClO}_{4}{ }^{-}$ signal decreased in the presence of these anions [86], which demonstrated their competitiveness in their adsorption onto the substrate, as Mosier-Boss et al. had previously stated [81]. Another relevant observation was made when using AuNPs which involved that $\mathrm{ClO}_{4}{ }^{-}$was not detected unless AuNPs were functionalized and positively charged $[84,85]$. In that sense, $\mathrm{ClO}_{4}{ }^{-}$anion needed SERS substrates functionalized with positively charged groups such as $-\mathrm{NH}_{2}$ or $-\mathrm{SH}$ to be attracted by the substrate and detected by SERS $[84,85]$. Gu et al. also studied the detection of $\mathrm{ClO}_{4}{ }^{-}$with real samples [86]. In fact, two real samples contaminated with $\mathrm{ClO}_{4}{ }^{-}$whose concentrations were $8.3 \times$ $10^{-6} \mathrm{M}$ and $1 \times 10^{-8} \mathrm{M}$, respectively (measured by IC (ion chromatography)), were properly detected and quantified by SERS since results were $7.86 \times 10^{-6} \mathrm{M}$ and $1.02 \times$ $10^{-8} \mathrm{M}$, respectively. That was an excellent demonstration of the capability of SERS for quantifying through the relationship between $\mathrm{ClO}_{4}^{-}$band intensity and its concentration [86].

Afterwards, Hao et al. continued the investigation of detecting $\mathrm{ClO}_{4}{ }^{-}$by SERS by using $\mathrm{Ag}$ nanofilms deposited on $\mathrm{Cu}$ foils $[87,88]$. By using those $\mathrm{Ag}-\mathrm{Cu}$ substrates, $\mathrm{ClO}_{4}{ }^{-}$was detected down to $5 \times 10^{-7} \mathrm{M}$ or $50 \mathrm{mg} / \mathrm{L}$ [87]. Actually, LOD was improved down to 5 $\mathrm{mg} / \mathrm{L}$ by using cysteamine functionalized $\mathrm{Ag} /$ roughened-Cu substrate [88]. In addition, a linear relationship between either peak area or peak intensity and concentration was observed along the concentrations range $0.05-1 \mathrm{mg} / \mathrm{L}[87,88]$ whereas the log-log relationship between peak intensity/area and concentration was linear for a broader range $(0.05-10 \mathrm{mg} / \mathrm{L})[87,88]$. Interestingly, the effect due to $\mathrm{pH}$ was also studied by this group 
in the $\mathrm{ClO}_{4}^{-}$detection by using the cysteamine functionalized $\mathrm{Ag} / \mathrm{Cu}$ substrate [88]. The highest intensity of $\mathrm{ClO}_{4}^{-}$signal was achieved for $\mathrm{pH}$ 6-7. Moreover, when $\mathrm{pH}$ was alkaline, $\mathrm{ClO}_{4}^{-}$signal almost vanished due to the deprotonation of amines from cysteamine which ceased from attracting $\mathrm{ClO}_{4}{ }^{-}$anion [88]. Reusability of substrates was also examined. By washing the substrate with water, $\mathrm{ClO}_{4}{ }^{-}$was completely removed and substrate could be reused. In fact, the same substrate was reused up to 10 times achieving good results, whereas in terms of time the substrate was usable along 5 days since its manufacture [88]. After that time, substrate was disabled due to Ag oxidation [88].

Finally, Nuntawong et al. studied the detection of $\mathrm{ClO}_{4}^{-}$from the point of view of detecting it as a component of explosives instead of a contaminant in water samples [89]. This pioneering study about detecting $\mathrm{ClO}_{4}^{-}$from IEDs by SERS was similar to those previously reviewed which were based on detecting military explosives (i.e., TNT, RDX). Perchlorates as well as other energetic salts such as nitrates and chlorates are increasingly being used as components in IEDs because of the easiness to obtain them from pyrotechnic devices. Nuntawong et al. analysed seven different explosives which contained some perchlorate and nitrate salts such as $\mathrm{KClO}_{4}$ and $\mathrm{NH}_{4} \mathrm{NO}_{3}$ by Raman and SERS in comparison to IC [89]. Nitrate and perchlorate were properly differentiated according to their respective Raman bands, i.e., $1054 \mathrm{~cm}^{-1}$ for nitrate and $934 \mathrm{~cm}^{-1}$ for perchlorate. Briefly, nitrate was detected in the all seven explosives whereas perchlorate was found in five of them [89]. As the authors stated, the detection of perchlorate is quite more suspicious than nitrate since perchlorate exclusively comes from explosive or pyrotechnic devices whereas nitrate is also used as fertilizer for example. What Nuntawong et al. demonstrated by comparing SERS and IC to detect $\mathrm{ClO}_{4}{ }^{-}$was mainly the lower time spent by using SERS. In fact, the $3 \mathrm{~h}$ per explosive, which were needed when using IC, seemed like an eternity in contrast with the 20 min needed for SERS measurements for the all seven explosives [89]. Furthermore, Nuntawong et al. also studied the applicability of SERS to detect $\mathrm{ClO}_{4}{ }^{-}$in post-blast explosive residues, an extremely hard challenging task. Interestingly, results demonstrated that intact residues of nitrate and perchlorate salts still remained among post-burnt residues since spectral bands due to nitrate and perchlorate were properly identified, as shown in Figure 5 [89]. According to authors, those results proved that SERS could be used as quick-screening tool for $\mathrm{ClO}_{4}^{-}$even for post-blast samples. 


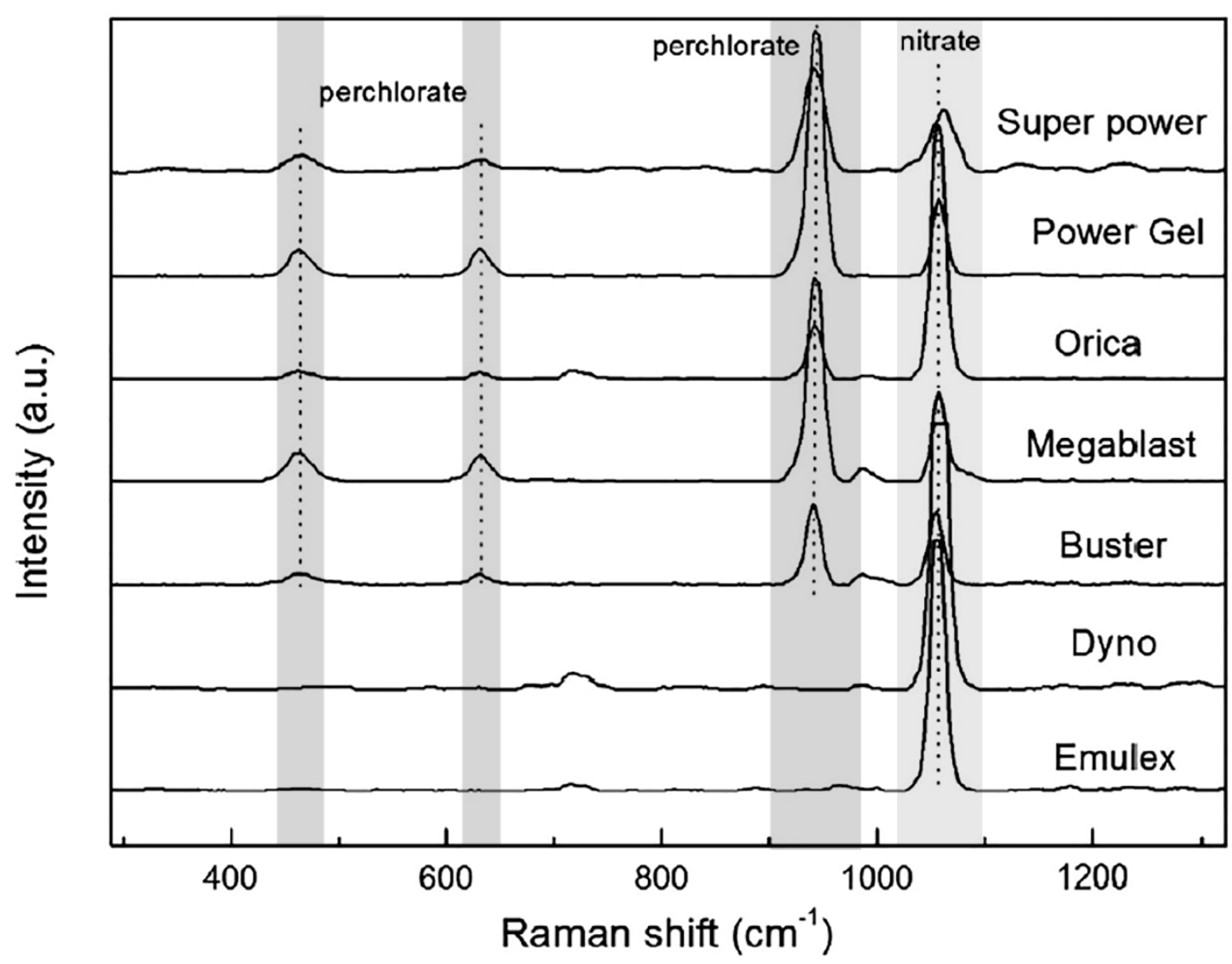

Figure 5. SERS spectra of seven water-dissolved explosives based on nitrate and perchlorate after being burned in an open flame. Adapted with permission from Nuntawong et al. (89).

\section{Conclusions and general concerns}

As can be noticed, explosives detection by SERS assembles a large number of studies which deal with the different issues previously reviewed. In summary, it seems that SERS is demonstrated to be a suitable technique for explosives detection. Undoubtedly, according to the results, SERS is eminently suitable for TNT detection. Around 40 papers prove the outstanding results accomplished for TNT detection by using SERS. Some of these studies achieved its detection down to fg $(19,20,47,48)$ and $10^{-15} \mathrm{M}$ levels [38, 49]. Furthermore, $5 \mathrm{zg}$ of TNT were surprisingly detected by Ko et al. [51] which is the equivalent of 15 molecules of TNT. However, LOD is not the unique factor which must be taken into consideration when testing the capabilities of an instrumental technique. Several troublesome aspects, which are discussed at the end of this section, delay the widespread use of SERS.

Apart from TNT and DNT, the rest of military explosives have been scarcely investigated by SERS. Fourteen papers summarize all this research with reference to RDX, PETN, 
EGDN, NG, HMX, DNAN, HNIW, and NTO explosives. LODs for these explosives were from $10^{-6}$ to $10^{-9} \mathrm{M}$ levels and ng to pg levels in terms of concentration and mass, respectively. These values are much more modest than LOD for TNT, which reveals that these compounds are perhaps less affected than TNT by SERS phenomenon. Nevertheless, even though this assumption was true, results are not so unsatisfactory for these explosives to discourage SERS technique. In fact, it is an advance to detect $10^{-6} \mathrm{M}$ levels of these military explosives by Raman spectroscopy. Further research will surely contribute to improve LODs for these explosives and to increase the number of explosives studied by SERS.

The detection of peroxide explosives represents undoubtedly a more challenging task. Because of their volatility and instability, the trace detection of TATP and HMTD by SERS is certainly complicated. According to a few studies [51, 64], this situation is even worst by using SERS because the laser exposition may induce the photodecomposition of these compounds. Novel methods to stabilize peroxide explosives and the use of milder conditions during SERS analysis must be explored in order to achieve properly the detection of TATP and HMTD by SERS.

The application of SERS to detect explosive vapours seems to be a very sensible idea, particularly with those explosives which have low vapour pressure such as DNT. In fact, DNT vapours also emanate from TNT so their detection and identification can be very revealing. Among reviewed studies, DNT vapour were detected down to $10 \mathrm{ppt}$ (around $\left.5 \times 10^{-11} \mathrm{M}\right)$ [72]. Other studies were focused on TNT vapour, which was detected down to $10^{-14} \mathrm{M}$ [77]. Finally, some studies were focused on TATP [69, 70, 78, 79] due to its high volatility. It could be detected down to $20 \mathrm{ppb}$ (around $10^{-7} \mathrm{M}$ ), which is a great LOD for TATP considering its instability. Taking into account the advances in TNT/DNT vapour detection by SERS previously reviewed and the current interest in chemical noses, it is just a matter of time that chemical sensors based on SERS are used to detect explosives containing TNT.

SERS has been also suitable to detect perchlorate anion, a harmful environmental contaminant that predominantly comes from explosives and pyrotechnic sources. LODs down to $10^{-9} \mathrm{M}$ have been achieved. In addition, its usefulness has been tested by analysing real samples including both contaminated water and pyrotechnic charges in comparison to IC, providing both techniques similar results. But, advantageously, SERS was much faster than IC, which encourages its use for real-time detection. 
It should be noted that SERS has been used to identify both organic (TNT, RDX, etc.) and inorganic (perchlorate and nitrate) explosive compounds. This feature is quite promising especially for on-field detection because it implies that any type of explosive either organic or inorganic could be detected by using one technique. Further investigation focusing on this multi-analyte detection is needed to overcome the widespread conception about SERS as a technique that is suitable for only a few analytes. In fact, that purpose is directed to the desired aim of using SERS for every analyte as occurs with normal Raman spectroscopy.

Regarding those troublesome aspects about SERS, first of all, the lack of reproducibility of some SERS substrates makes the trace detection really difficult. As previously discussed, the analyte deposition on the substrate is usually not uniform; therefore the amount of analyte differs from spot to spot. This fact inevitably implies that several measures from different spots have to be accomplished in order to ensure a representative result, and moreover, we do not know the accurate mass in each spot. Hence, some authors have tried to estimate it. However, LOD estimates calculated by considering the total mass uniformly distributed along the substrate and focused on the laser spot area may lead to erroneous and unrealistic values. In fact, all LODs provided in terms of mass come from those doubtful estimates. Other authors have opted to provide LODs in terms of concentration either molar concentration or mass concentration $(\mathrm{mg} / \mathrm{L}$ or $\mathrm{ppm})$ in order to avoid those estimates. That is, the concentration of the solution added to the substrate. Nevertheless, adding $10 \mathrm{~mL}$, for example, is not the same as adding $0.1 \mathrm{~mL}$. It is necessary to specify the added volume to the substrate when providing LODs by concentration. Even so, that volume is not the amount of analyte that is providing the SERS signal since it comes from the molecules of analyte within the laser spot as stated by the authors who defend its mass estimate. Undoubtedly, it would be beneficial to reach a consensus on this point in order to all provide comparable and consistent results. A useful recommendation (followed in Table 1) would be that the volume and the concentration of the solution added to the SERS substrate should be always provided regardless of whether LOD is subsequently estimated within the laser spot or not.

On the other hand, SERS signal differences along the substrate are not uniquely due to the mass which is being analysed. Even though all molecules of the analyte were homogeneously distributed along the substrate, intensity differences could exist due to the different interaction between these molecules and metal surface, which is responsible 
for the enhancement. In order to overcome this limitation, different ways to improve and control the interaction between molecules of analyte and metal surface have been studied. Interestingly, the deposition of the analyte along the substrate previously discussed is influenced to a certain extent by that interaction. Therefore, we can promote a homogeneous deposition by controlling that interaction. Gold and silver NPs and foils of different sizes, forms, and thicknesses have been examined for TNT detection. In addition, the presence or absence of $\mathrm{NaCl}$ has been tested. However, what seems to highly improve the interaction and consequently the SERS signal is the chemical functionalization of metal surface. Specifically, amino-thio-compounds such as PATP, cysteine or cysteamine have demonstrated to be highly suitable for TNT. Particularly, the thiol group interacts with $\mathrm{Au}$ or $\mathrm{Ag}$ whereas the amino group interacts with nitro groups from TNT through p-donor-acceptor interactions forming a Meisenheimer complex. By means of these interactions, both LODs and selectivity of SERS are surprisingly enhanced. In fact, if the metal surface was not functionalized, any chemical compound could potentially contribute to the resulting Raman spectrum, which would make realworld samples difficult to be analysed. This matter has not been deeply studied yet because almost all the reviewed studies were focused on detecting standards solutions of each explosive where SERS signal can uniquely come from the molecules of explosive. The investigation of real explosive samples is mandatory in order to test the viability of SERS in real conditions beyond academic field. And, undoubtedly, functionalization is a sensible approach to overcome the indiscriminate enhancement of SERS focusing, thereby, on the target molecule.

However, further research in functionalization of SERS substrates is required because, up until now, these functionalizations have been widely tested only for TNT and, perhaps, DNT detection. The rest of explosives have been scarcely studied, therefore specific functionalizations must be explored for each explosive. Actually, it could be enough to develop functionalizations for each family of explosives including nitroaromatic explosives, nitro-esters, peroxides, nitrates and perchlorates. Nevertheless, we have already checked in different studies that there are some chemical functionalizations which surprisingly enhanced TNT signal but they do not enhance too much DNT signal (being only the difference one nitro group in the molecule).

In addition, functionalization makes SERS detection a bit more laborious because of the necessity of the addition of an extra component to the SERS mixture (sample + NPs or 
metal foil). It is properly said that Raman spectroscopy is a non-destructive and noninvasive technique. However, that is not the case when using SERS. SERS is also nondestructive but it is seriously invasive. This fact can be very unfavourable for forensic purposes in which the preservation of the evidence is mandatory. Although it is true that the evidence would be kept on the SERS substrate, the evidence would actually be captured by the substrate. In fact, if forensic practitioners needed to extract the evidence from the SERS substrate in order to analyse it by means of another analytical technique for example, it would be practically impossible.

Besides the prevention of real threats by means of detecting explosive devices before their explosion, which is undoubtedly the most important aim, the forensic detection of explosives evidence is also a critical aspect. The knowledge of the explosives involved can support information about the terrorists or criminals behind the attack, and it provides useful information to prevent future threats. However, the detection of post-blast residues is extremely challenging. Almost all the explosive charge is consumed during the explosion, and the explosives traces that remain are widely dispersed along innumerable burnt and devastated materials because of the explosion. Among the reviewed studies, very few have dealt with real post-blast explosive residues. In fact, only Nuntawong et al. have dealt with the detection of post-blast evidence based on perchlorate. Thus, specific investigation focused on post-blast evidence detection is required.

\section{References}

[1] Marshall, M. and Oxley, J. (2009) Aspects of Explosives Detection. Elsevier: Netherlands.

[2] Bailey, A. and Murray, S.G. (2000) Explosives, Propellants and Pyrotechnics. Brassey's: London, UK.

[3] Yinon, J. (2007) Counterterrorist Detection Techniques of Explosives. Elsevier: Netherlands.

[4] Hwang, J., Choi, N., Park, A., Park, J., Chung, J.H., Baek, S., Cho, S.G., Baek, S., and Choo, J. (2013) Fast and sensitive recognition of various explosive compounds using Raman spectroscopy and principal component analysis. J. Mol. Struc., 1039: 130-136.

[5] Moros, J., Lorenzo, J.A., Novotny, K., and Laserna, J.J. (2013) Fundamentals of stand-off Raman scattering spectroscopy for explosive fingerprinting. J. Raman Spectrosc., 44: 121130.

[6] Almaviva, S., Botti, S., Cantarini, L., Palucci, A., Schnuerer, F., Schweikert, W., and Romolo, F.S. (2013) Raman spectroscopy for the detection of explosives and their precursors on 
clothing in fingerprint concentration: a reliable technique for security and counterterrorist issues. Proc. SPIE, 8901: 890102/1-890102/9.

[7] López-López, M. and García-Ruiz, C. (2014) Infrared and Raman spectroscopy techniques applied to identification of explosives. Trends Anal. Chem., 54: 36-44.

[8] López-López, M., Ferrando, J.L., and García-Ruiz, C. (2013) Dynamite analysis by Raman spectroscopy as a unique analytical tool. Anal. Chem., 85: 2595-2600.

[9] Ali, E.M.A., Edwards, H.G.M., Hargreaves, M.D., and Scowen I.J. (2009) Detection of explosives on human nail using confocal Raman microscopy. J. Raman Spectrosc., 40: 144149.

[10] Pacheco-Londoño, L.C., Ortiz-Rivera, W., Primera-Pedrozo, O.M., and HernandezRivera, S.P. (2009) Vibrational spectroscopy standoff detection of explosives. Anal. Bioanal. Chem., 395: 323-335.

[11] Docherty, F.T., Monaghan, P.B., McHugh, C.J., Graham, D., Smith, W.E., and Cooper, J.M. (2005) Simultaneous multianalyte identification of molecular species involved in terrorism using Raman spectroscopy. IEEE Sens. J., 5: 632-640.

[12] Aoki, P.H.B., Furini, L.N., Alessio, P., Aliaga, A.E., and Constantino, C.J.L. (2013) Surfaceenhanced Raman scattering (SERS) applied to cancer diagnosis and detection of pesticides, explosives, and drugs. Rev. Anal. Chem., 32: 55-76.

[13] Kneipp, K., Kneipp, H., Itzkan, I., Dasary, R.R. and Feld, M.S. (1999) Ultrasensitive chemical analysis by Raman spectroscopy. Chem. Rev., 99: 2957-2975.

[14] McQuillan, A.J. (2009) The discovery of surface-enhanced Raman scattering. Notes Rec. R. Soc., 63: 105-109.

[15] Fleischmann, M., Hendra, P.J., and McQuillan, A.J. (1974) Raman spectra of pyridine adsorbed at a silver electrode. Chem. Phys. Lett., 26: 163-166.

[16] Golightly, R.S., Doering, W.E., and Natan, M.J. (2009) Surface-enhanced Raman spectroscopy and homeland security: a perfect match? ACS Nano, 3: 2859-2869.

[17] Kneipp, K., Wang, Y., Dasari, R.R., Feld, M.S., Gilbert, B.D., Janni, J., and Steinfeld, J.I. (1995) Near-infrared surface-enhanced Raman scattering of trinitrotoluene on colloidal gold and silver. Spectrochim. Acta A, 51: 2171-2175.

[18] Haas, J.W., Sylvia, J.M., Spencer, K.M., Johnston, T.M., and Clauson, S.L. (1998) Surfaceenhanced Raman sensor for nitroexplosive vapors. Proc. SPIE, 3392: 469-476.

[19] Jerez-Rozo, J.I., Chamoun, A.M., Peña, S.L., and Hernández-Rivera, S.P. (2007) Enhanced Raman Scattering of TNT on Nanoparticle Substrates: Ag Colloids Prepared by Reduction with Hydroxylamine Hydrochloride and Sodium Citrate. Proc. SPIE, 6538: 653824/1-653824/12. 
[20] Jerez-Rozo, J.I., Primera-Pedrozo, O.M., Barreto-Cabán, M.A., and Hernández-Rivera, S.P. (2008) Enhanced Raman scattering of 2,4,6-TNT using metallic colloids. IEEE Sensors J., 8: 974-982.

[21] Lee, P.C. and Meisel, D. (1982) Adsorption and surface-enhanced Raman of dyes on silver and gold sols. J. Phys. Chem., 86: 3391-3395.

[22] Leopold, N. and Lendl, B. (2003) A New Method for Fast Preparation of Highly SurfaceEnhanced Raman Scattering (SERS) Active Silver Colloids at Room Temperature by Reduction of Silver Nitrate with Hydroxylamine Hydrochloride. J. Phys. Chem. B, 107: $5723-5727$.

[23] Zhang, C., Wang, K., Han, D., and Pang, Q. (2014) Surface enhanced Raman scattering (SERS) spectra of trinitrotoluene in silver colloids prepared by microwave heating method. Spectrochim. Acta A, 122: 387-391.

[24] Sil, S., Chaturvedi, D., Krishnappa, K.B., Kumar, S., Asthana, S.N., and Umapathy, S. (2014) Density functional theoretical modeling, electrostatic surface potential and surface enhanced Raman spectroscopic studies on biosynthesized silver nanoparticles: observation of 400 pM sensitivity to explosives. Phys. Chem. A, 118: 2904-2914.

[25] Fierro-Mercado, P.M. and Hernández-Rivera, S.P. (2012) Highly sensitive filter paper substrate for SERS trace explosives detection. Int. J. Spectrosc., 716527.

[26] Calzzani, F.A., Sileshi, R., Kassu, A., Taguenang, J.M., Chowdhury, A., Sharma, A., Ruffin, P.B., Brantley, C., and Edwards, E. (2008) Detection of residual traces of explosives by surface enhanced Raman scattering using gold coated substrates produced by nanospheres imprint technique. Proc. SPIE, 6945: 694510/1-694510/9.

[27] Botti, S., Cantarini, L., and Palucci, A. (2010) Surface-enhanced Raman spectroscopy for trace level detection of explosives. J. Raman Spectrosc., 41: 866-869.

[28] Botti, S., Carpanese, M., Cantarini, L., Giubileo, G., Lazic, V., Jovicevic, S., Palucci, A., and Puiu, A. (2010) Trace detection of explosive compounds by different laser-based techniques at the ENEA laboratories. Proc. SPIE, 7665: 766500/1-766500/12.

[29] Almaviva, S., Botti, S., Cantarini, L., Palucci, A., Puiu, A., Rufoloni, A., Landstr€om, L., and Romolo, F.S. (2012) Trace detection of explosives by surface enhanced Raman spectroscopy. Proc. SPIE, 8546: 854602/1-854602/7.

[30] Botti, S., Almaviva, S., Cantarini, L., Palucci, A., Puiu, A., and Rufoloni, A. (2013) Trace level detection and identification of nitro-based explosives by surface-enhanced Raman spectroscopy. J. Raman Spectrosc., 44: 463-468.

[31] Botti, S., Cantarini, L., Almaviva, S., Puiu, A., and Rufoloni, A. (2014) Assessment of SERS activity and enhancement factors for highly sensitive gold coated substrates probed with explosive molecules. Chem. Phys. Lett., 592: 277-281. 
[32] Almaviva, S., Botti, S., Cantarini, L., Fantoni, R., Lecci, S., Palucci, A., Puiu, A., and Rufoloni, A. (2014) Ultrasensitive RDX detection with commercial SERS substrates. J. Raman Spectrosc., 45: 41-46.

[33] Yang, L., Ma, L., Chen, G., Liu, J., and Tian, Z. Q. (2010) Ultrasensitive SERS detection of TNT by imprinting molecular recognition using a new type of stable substrate.Chem. Eur. J., 16: 12683-12693.

[34] Holthoff, E.L., Stratis-Cullum, D.N., and Hankus, M.E. (2010) Xerogel-based molecularly imprinted polymers for explosives detection. Proc. SPIE, 7665: 76650W/1$76650 \mathrm{~W} / 9$.

[35] Holthoff, E.L., Stratis-Cullum, D.N., and Hankus, M.E. (2011) A nanosensor for TNT detection based on molecularly imprinted polymers and surface enhanced Raman scattering. Sensors, 11: 2700-2714.

[36] Dasary, S.S.R., Singh, A.K., Senapati, D., Yu, H., and Ray, P.C. (2009) Gold nanoparticle based label-Free SERS probe for ultrasensitive and selective detection of trinitrotoluene. JACS, 131: 13806-13812.

[37] Glembocki, O.J., Gowda, M., Geng, S., Prokes, S.M., Garces, N.Y., Cushen, J., and Caldwell, J.D. (2010) Cysteamine coated Ag and Au nanorods for improved surface enhanced Raman scattering form dinitrotoluene and trinitrotoluene. Proc. SPIE, 7757: 77570I/1$77570 \mathrm{I} / 9$.

[38] Zhou, H., Zhang, Z., Jiang, C., Guan, G., Zhang, K., Mei, Q., Liu, R., and Wang, S. (2011) Trinitrotoluene explosive lights up ultrahigh Raman scattering of nonresonant molecule on a top-closed silver nanotube array. Anal. Chem., 83: 6913-6917.

[39] Liu, X., Zhao, L., Shen, H., Xu, H., and Lu, L. (2011) Ordered gold nanoparticle arrays as surfaceenhanced Raman spectroscopy substrates for label-free detection of nitroexplosives. Talanta, 83: 1023-1029.

[40] Xu, J.Y., Wang, J., Kong, L.T., Zheng, G.C., Guo, Z., and Liu, J.H. (2011) SERS detection of explosive agent by macrocyclic compound functionalized triangular gold nanoprisms. J. Raman Spectrosc., 42: 1728-1735.

[41] Liu, M. and Chen, W. (2013) Graphene nanosheets-supported Ag nanoparticles for ultrasensitive detection of TNT by surface-enhanced Raman spectroscopy. Biosens. Bioelectron., 46: 68-73.

[42] He, X., Wang, H., Li, Z., Chen, D., and Zhang, Q. (2014) ZnO-Ag hybrids for ultrasensitive detection of trinitrotoluene by surface-enhanced Raman spectroscopy. Phys. Chem. Chem. Phys., 16: 14706-14712.

[43] Cruz-Montoya, E., Blanco, A., Balaguera-Gelves, M., Pacheco-Londoño, L., and Hernández-Rivera, S.P. (2005) Surface Enhanced Raman Scattering of Nitroexplosives on non traditional substrates. Proc. SPIE, 5778: 359-367. 
[44] Cruz-Montoya, E. (2005) Surface enhanced Raman scattering of nitro explosives on titanium oxide substrates, Abstracts of Papers, 230th ACS National Meeting, Washington, DC, United States, Aug. 28-Sept. 1, 2005. Pages: COLL-208.

[45] Jeréz-Rozo, J.I., Balaguera, M.R., Cabanzo, A., Cruz-Montoya, E., and HernándezRivera, S.P. (2006) Enhanced Raman scattering of nitro-explosives on nanoparticles substrates: Au-Ag alloy, tin oxide, and scandium oxide. Proc. SPIE, 6201: 62012G/1$62012 \mathrm{G} / 8$.

[46] Cruz-Montoya, E., Jeréz, J.I., Balaguera-Gelves, M., Luna-Pineda, T., Castro, M.E., and Hernández-Rivera, S.P. (2006) Enhanced Raman spectroscopy of 2,4,6-TNT in anatase and rutile titania nanocrystals. Proc. SPIE, 6203: 62030X/—62030X/7.

[47] Primera-Pedrozo, O.M., Jerez-Rozo, J.I., Cruz-Montoya, E., Luna-Pineda, T., PachecoLondoño, L.C., and Hernández-Rivera, S.P. (2008) Nanotechnology-based detection of explosives and biological agents simulants. IEEE Sens., 8: 963-973.

[48] Hernández-Rivera, S.P., Briano, J.G., Cruz-Montoya, E., Perez-Acosta, G.A., and JerezRozo, J.I. (2009) Enhanced Raman scattering of nitro-explosives on metal oxides and Ag/TiO2 nanoparticles. ACS Symposium Series, 1016: Nanoscience and Nanotechnology for Chemical and Biological Defense, 205-216.

[49] Shao, M.W., Lu, L., Wang, H., Wang, S., Zhang, M.L., Ma, D., and Lee, S.T. (2008) An ultrasensitive method: surface-enhanced Raman scattering of Ag nanoparticles from b-silver vanadate and copper. Chem. Commun., 20: 2310-2312.

[50] Ko, H. and Tsukruk, V.V. (2008) Nanoparticle-decorated nanocanals for surfaceenhanced Raman scattering. Small, 4: 1980-1984.

[51] Ko, H., Chang, S., and Tsukruk, V.V. (2009) Porous substrates for label-free molecular level detection of nonresonant organic molecules. ACS Nano, 3: 181-188.

[52] Sajanlal, P.R. and Pradeep, T. (2012) Functional hybrid nickel nanostructures as recyclable SERS substrates: detection of explosives and biowarfare agents. Nanoscale, 4 : $3427-3437$.

[53] Demeritte, T., Kanchanapally, R., Fan, Z., Singh, A. K., Senapati, D., Dubey, M., Zakar, E., and Ray, P.C. (2012) Highly efficient SERS substrate for direct detection of explosive TNT using popcorn- shaped gold nanoparticle-functionalized SWCNT hybrid. Analyst, 137: 5041-5045.

[54] Talian, I. and Huebner, J. (2013) Separation followed by direct SERS detection of explosives on a novel black silicon multifunctional nanostructured surface prepared in a microfluidic channel. J. Raman Spectrosc., 44: 536-539.

[55] Kanchanapally, R., Sinha, S.S., Fan, Z., Dubey, M., Zakar, E., and Ray, P.C. (2014) Graphene oxide-gold nanocage hybrid platform for trace level identification of nitro explosives using a Raman fingerprint. J. Phys. Chem. C, 118: 7070-7075. 
[56] Mahmoud, K.A. and Zourob, M. (2013) Fe3O4/Au nanoparticles/lignin modified microspheres as effectual surface enhanced Raman scattering (SERS) substrates for highly selective and sensitive detection of 2,4,6-trinitrotoluene (TNT). Analyst, 138: 2712-2719.

[57] McHugh, C.J., Keir, R., Graham, D., and Smith, W.E. (2002) Selective functionalization of TNT for sensitive detection by SERRS. Chem. Comm., 2002: 580-581.

[58] Keir, R., Igata, E., Arundell, M., Smith, W.E., Graham, D., McHugh, C., and Cooper, J. M. (2002) SERRS. In situ substrate formation and improved detection using microfluidics. Anal. Chem., 74: 1503-1508.

[59] Liu, H., Lin, D., Sun, Y., Yang, L., and Liu, J. (2013) Cetylpyridinium chloride activated trinitrotoluene explosive lights up robust and ultrahigh surface-enhanced resonance Raman scattering in a silver sol. Chem. Eur. J., 19: 8789-8796.

[60] Hatab, N.A., Eres, G., Hatzinger, P.B., and Gu, B. (2010) Detection and analysis of cyclotrimethylenetrinitramine (RDX) in environmental samples by surface-enhanced Raman spectroscopy. J. Raman Spectrosc., 41: 1131-1136.

[61] Xu, Z., Hao, J., Braida, W., Strickland, D., Li, F., and Meng, X. (2011) Surface-enhanced Raman scattering spectroscopy of explosive 2,4-dinitroanisole using modified silver nanoparticles. Langmuir, 27: 13773-13779.

[62] Xu, Z. and Meng, X. (2012) Detection of 3-nitro-1,2,4-triazol-3-one (NTO) by surfaceenhanced Raman spectroscopy. Vibrat. Spectrosc., 63: 390-395.

[63] Oxley, J., Smith, J., Brady, J., Dubnikova, F., Kosloff, R., Zeiri, L., and Zeiri, Y. (2008) Raman and infrared fingerprint spectroscopy of peroxide-based explosives. Appl. Spect., 62: 906-915.

[64] Chang, S., Ko, H., Singamaneni, S., Gunawidjaja, R., and Tsukruk, V.V. (2009) Nanoporous membranes with mixed nanoclusters for Raman-based label-free monitoring of peroxide compounds. Anal. Chem., 81: 5740-5748.

[65] Spencer, K.M., Sylvia, J.M., Janni, J.A., and Klein, J.D. (1999) Advances in landmine detection using surface-enhanced Raman spectroscopy. Proc. SPIE, 3710: 373-379.

[66] Sylvia, J.M., Spencer, K.M., and Janni, J.A. (2000) Sniffing landmines with surfaceenhanced Raman spectroscopy. JPAC, 146-147.

[67] Sylvia, J.M., Janni, J.A., Klein, J.D., and Spencer, K.M. (2000) Surface-enhanced Raman detection of 2,4-dinitrotoluene impurity vapor as a marker to locate landmines. Anal. Chem., 72: $5834-5840$.

[68] Spencer, K.M., Sylvia, J.M., Marren, P.J., Bertone, J.F., and Christesen, S.D. (2004) Surface enhanced Raman spectroscopy for homeland defense. Proc. SPIE, 5269: 1-8.

[69] Gundrum, L., Hüttner, W. and Wackerbarth, H. (2010) Detection of explosives based on surface enhanced Raman spectroscopy, Application note, Laser-Laboratorium Göttingen, University of Göttingen, Germany. 
[70] Wackerbarth, H., Salb, C., Gundrum, L., Niederkrüger, M., Christou, K., Beushausen, V., and Viöl, W. (2010) Detection of explosives based on surface-enhanced Raman spectroscopy. Appl. Opt., 49: 4362-4366.

[71] Wackerbarth, H., Gundrum, L., Salb, C., Christou, K,. and Viöl, W. (2010) Challenge of false alarms in nitroaromatic explosive detection-a detection device based on surfaceenhanced Raman spectroscopy. Appl. Opt 49: 4367-4371.

[72] Wang, J., Yang, L., Boriskina, S., Yan, B., and Reinhard, B.M. (2011) Spectroscopic ultra-trace detection of nitroaromatic gas vapor on rationally designed two-dimensional nanoparticle cluster arrays. Anal. Chem., 83: 2243-2249.

[73] Oo, M.K.K., Chang, C.F., Sun, Y., and Fan, X. (2011) Rapid, sensitive DNT vapor detection with UV assisted photo-chemically synthesized gold nanoparticle SERS substrates. Analyst, 136: 2811-2817.

[74] Piorek, B.D., Lee, S.J., Moskovits, M., and Meinhart, C.D. (2012) Free-surface microfluidics/surface- enhanced raman spectroscopy for real-time trace vapor detection of explosives. Anal. Chem., 84: 9700-9705.

[75] Chou, A., Jaatinen, E., Buividas, R., Seniutinas, G., Juodkazis, S., Izake, E.L., and Fredericks, P.M. (2012) SERS substrate for detection of explosives. Nanoscale, 4: 74197424.

[76] Büttner, F., Hagemann, J., Wellhausen, M., Funke, S., Lenth, C., Rotter, F., Gundrum, L., Plachetka, U., Moormann, C., Strube, M., Walte, A., and Wackerbarth, H. (2013) Surface enhanced vibrational spectroscopy for the detection of explosives. Proc. SPIE, 8896: 889609/1-889609/12.

[77] Wang, J., Yang, L., Liu, B., Jiang, H., Liu, R., Yang, J., Han, G., Mei, Q., and Zhang, Z. (2014) Inkjet- printed silver nanoparticle paper detects airborne species from crystalline explosives and their ultratrace residues in open environment. Anal. Chem., 86: 3338-3345.

[78] Fang, X. and Ahmad, S.R. (2009) Detection of explosive vapor using surface-enhanced Raman spectroscopy. Appl. Phys. B, 97: 723-726.

[79] Spencer, K.M., Clauson, S.L., and Sylvia, J.M. (2011) Development of a fieldable rugged TATP surface-enhanced Raman spectroscopy sensor. Proc. SPIE, 8032: 80320L/180320L/9.

[80] Niaura, G. and Malinauskas, A. (1998) Surface-enhanced Raman spectroscopy of $\mathrm{ClO}_{4}^{-}$ and $\mathrm{SO}_{4}{ }^{2-}$ anions adsorbed at a $\mathrm{Cu}$ electrode. J. Chem. Soc. Faraday Trans 94: 2205-2211.

[81] Mosier-Boss, P.A. and Lieberman, S.H. (2003) Detection of anions by normal Raman spectroscopy and surface-enhanced Raman spectroscopy of cationic-coated substrates. Appl. Spect., 57: 1129-1137.

[82] Gu, B., Tio, J., Wang, W., Ku, Y.K., and Dai, S. (2004) Raman spectroscopic detection for perchlorate at low concentrations. Appl. Spect., 58: 741-744. 
[83] Wang, W. and Gu, B. (2005) New surface-enhanced Raman spectroscopy substrates via self-assembly of silver nanoparticles for perchlorate detection in water. Appl. Spect., 59: $1509-1515$.

[84] Ruan, C., Wang, W., and Gu, B. (2006) Surface-enhanced Raman scattering for perchlorate detection using cystamine-modified gold nanoparticles. Anal. Chim. Acta, 567: $114-120$.

[85] Wang, W., Ruan, C., and Gu, B. (2006) Development of gold-silica composite nanoparticles substrates for perchlorate detection by surface-enhanced Raman spectroscopy. Anal. Chim. Acta, 567: 121-126.

[86] Gu, B., Ruan, C., and Wang, W. (2009) Perchlorate detection at nanomolar concentrations by surface- enhanced Raman scattering. Appl. Spect., 63: 98-102.

[87] Hao, J., Xu, Z., Han, M. J., Xu, S., and Meng, X. (2010) Surface-enhanced Raman scattering analysis of perchlorate using silver nanofilms deposited on copper foils. Colloids Surf. A, 366: 163-169.

[88] Hao, J., Han, M.J., Li, J., and Meng, X. (2012) Surface modification of silver nanofilms for improved perchlorate Detection by surface-enhanced Raman scattering. J. Colloid Interf. Sci., 377: 51-57.

[89] Nuntawong, N., Eiamchai, P., Limwichean, S., Wong-ek, B., Horprathum, M., Patthanasettakul, V., Leelapojanaporn, A., Nakngoenthong, S., and Chindaudom, P. (2013) Trace detection of perchlorate in industrial-grade emulsion explosive with portable surfaceenhanced Raman spectroscopy. Forensic Sci. Int., 233: 174-178. 